\title{
Supporting Information: \\ $\alpha, \beta$-Unsaturated 2-acyl imidazoles as a practical class of dienophiles for the DNA-based catalytic asymmetric Diels-Alder reaction in water
}

\author{
Arnold J. Boersma, Ben L. Feringa,* and Gerard Roelfes* \\ Department of Organic and Molecular Inorganic Chemistry, \\ Stratingh Institute for Chemistry, University of Groningen, \\ Nijenborgh 4, 9747 AG Groningen, The Netherlands.
}

General Remarks.

Salmon testes DNA was obtained from Sigma. Ligands L1-L4, ${ }^{1}$ copper complexes of L5-L7, ${ }^{2}$ dienophiles $\mathbf{1 a}$ and $\mathbf{1 g},{ }^{3}$ and dienophiles $\mathbf{1 b}, \mathbf{1 c}, \mathbf{1 d}$, and $\mathbf{1 \mathrm { e } ^ { 4 }}$ were prepared following published procedures. Cyclopentadiene was freshly prepared from its dimer prior to use. ${ }^{1} \mathrm{H}-\mathrm{NMR}$, and ${ }^{13} \mathrm{C}-\mathrm{NMR}$ spectra were recorded on a Varian 400 (400 and $100 \mathrm{MHz})$ or Varian $300(300$ and $75 \mathrm{MHz})$ in $\mathrm{CDCl}_{3}$. Chemical shifts $(\delta)$ are quoted in ppm using residual solvent as internal standard $\left(\delta_{\mathrm{C}} 77.0\right.$ and $\delta_{\mathrm{H}} 7.26$ for $\left.\mathrm{CDCl}_{3}\right)$. Mass spectra (HRMS) were recorded on an AEI MS-902. Optical rotations were measured on a Schmidt and Haensch Polartronic MH8. Enantiomeric excess determination was performed by HPLC analysis using UV-detection. Flash chromatography was performed using silica gel $60 \AA$ (Merck, 200-400 mesh).

\section{Representative procedure $\mathrm{Cu}(\mathrm{L})\left(\mathrm{NO}_{3}\right)_{2} / \mathrm{DNA}$ catalyzed Diels-Alder cycloaddition.}

A catalyst solution of $\mathrm{Cu}(\mathbf{L} 7)\left(\mathrm{NO}_{3}\right)_{2}(0.3 \mathrm{mM})$ and salmon testes DNA $(1.3 \mathrm{mg} / \mathrm{mL})$ in $20 \mathrm{mM}$ MOPS buffer, $\mathrm{pH}$ 6.5, was prepared by adding to a solution of $\mathrm{Cu}(\mathbf{L} 7)\left(\mathrm{NO}_{3}\right)_{2}$ in water $(5 \mathrm{~mL}$, final concentration $0.9 \mathrm{mM})$, a salmon testes DNA solution $(10 \mathrm{~mL}, 2 \mathrm{mg} / \mathrm{mL}$ in $30 \mathrm{mM}$ MOPS buffer, $\mathrm{pH} 6.5$; prepared $24 \mathrm{~h}$ in advance). To this was added $30 \mu \mathrm{L}$ of a stock solution of dienophile $1 \mathrm{a}(0.5 \mathrm{M}$ in DMSO). After addition of cyclopentadiene $(20 \mu \mathrm{L}$, final concentration $15 \mathrm{mM})$ the reaction was mixed 3 days by continuous inversion at $5{ }^{\circ} \mathrm{C}$. The product was isolated by extraction with EtOAc. After drying $\left(\mathrm{Na}_{2} \mathrm{SO}_{4}\right)$ and removal of the solvent the crude product was analyzed by NMR and HPLC. Subsequently, the product was purified by column chromatography, and analyzed by HPLC.

\section{Synthesis dienophiles}

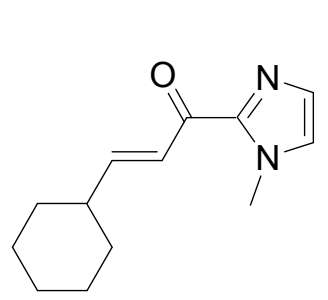

3-Cyclohexyl-1-(1-methyl-1H-imidazol-2-yl)-propenone (1f)

A solution of 2-acetyl-1-methylimidazole ${ }^{5}(1.2 \mathrm{~g}, 10 \mathrm{mmol})$, cyclohexane carbaldehyde $(1.1 \mathrm{~g}, 10 \mathrm{mmol})$, and $\mathrm{KOH}(0.1 \mathrm{~g})$ in $20 \mathrm{~mL}$ EtOH was stirred overnight. After addition of brine (30 $\mathrm{mL})$ and water $(10 \mathrm{~mL})$ the mixture was extracted with EtOAc $(3 \times 75 \mathrm{~mL})$. The organic fractions were combined and dried on sodium sulfate. After concentration the crude product was purified using column chromatography $\left(\mathrm{SiO}_{2}, 30 \%\right.$ EtOAc:hexanes) giving it as a colourless oil $(0.33 \mathrm{~g}, 15 \%)$. ${ }^{1} \mathrm{H}-\mathrm{NMR}\left(\mathrm{CDCl}_{3}, 400 \mathrm{MHz}\right) \delta 1.02-1.28(\mathrm{~m}, 5 \mathrm{H}), 1.53-$ $1.76(\mathrm{~m}, 5 \mathrm{H}), 2.13-2.19(\mathrm{~m}, 1 \mathrm{H}), 3.95(\mathrm{~s}, 3 \mathrm{H}), 6.96(\mathrm{~s}, 1 \mathrm{H}), 6.98(\mathrm{dd}, 1 \mathrm{H}, \mathrm{J}=15.8 \mathrm{~Hz}$, 
$\mathrm{J}=6.8), 7.07(\mathrm{~s}, 1 \mathrm{H}), 7.28(\mathrm{dd}, 1 \mathrm{H}, \mathrm{J}=15.8 \mathrm{~Hz}, \mathrm{~J}=1.4 \mathrm{~Hz}) .{ }^{13} \mathrm{C}-\mathrm{NMR}\left(\mathrm{CDCl}_{3}, 100\right.$ $\mathrm{MHz}) \delta 25.9(\mathrm{t}), 26.1(\mathrm{t}), 31.9(\mathrm{t}), 36.4(\mathrm{q}), 41.0(\mathrm{~d}), 123.9$ (d), 127.2 (d), 129.3 (d), 153.7 (d), 155.3 (s), 181.9 (s). HRMS Calcd for $\mathrm{C}_{13} \mathrm{H}_{18} \mathrm{~N}_{2} \mathrm{O}$ 218.1419, found 218.1408 .

\section{1-(1-Methyl-1H-imidazol-2-yl)-propenone (1h)}<smiles>C=CC(=O)c1nccn1C</smiles>

To a solution of 1-methylimidazole $(0.51 \mathrm{~g}, 6.2 \mathrm{mmol})$ in $20 \mathrm{~mL}$ THF cooled to $-78{ }^{\circ} \mathrm{C}$, was added $3.9 \mathrm{~mL}$-BuLi (1.6 M in hexanes). After stirring for 5 minutes the solution was slowly warmed to room temperature, followed by cooling back to $-78{ }^{\circ} \mathrm{C}$. Dropwise addition of acrolein $(0.35 \mathrm{~g}, 6.2 \mathrm{mmol})$ resulted in a colour change to red. Loss of colour was observed after the addition was completed. The mixture was quenched with water $(6.5$ $\mathrm{mL}$ ), warmed to room temperature, and $60 \mathrm{~mL}$ water and $60 \mathrm{~mL}$ EtOAc were added. The layers were separated and the water layer was extracted with EtOAc. The combined organic layers were dried on $\mathrm{Na}_{2} \mathrm{SO}_{4}$, filtered and concentrated. The crude residue was dissolved in $30 \mathrm{~mL} \mathrm{CH} \mathrm{Cl}_{2} . \mathrm{MnO}_{2}$ (5 g, $57 \mathrm{mmol}$ ) was added, and the reaction was stirred vigorously at room temperature for 45 minutes. The reaction mixture was filtered over a celite pad and concentrated. After purification over a short column $\left(\mathrm{SiO}_{2}, \mathrm{EtOAc}\right) \mathbf{1 h}(0.20 \mathrm{~g}, 24 \%)$ was obtained as a colourless oil, which was used immediately. ${ }^{1} \mathrm{H}-\mathrm{NMR}\left(\mathrm{CDCl}_{3}, 400 \mathrm{MHz}\right) \delta 4.02(\mathrm{~s}, 3 \mathrm{H}), 5.83(\mathrm{dd}, 1 \mathrm{H}, \mathrm{J}=10.4$ $\mathrm{Hz}, \mathrm{J}=2.0 \mathrm{~Hz}), 6.48(\mathrm{dd}, 1 \mathrm{H}, \mathrm{J}=17.5 \mathrm{~Hz}, \mathrm{~J}=1.8 \mathrm{~Hz}), 7.04(\mathrm{~s}, 1 \mathrm{H}), 7.16(\mathrm{~s}, 1 \mathrm{H}), 7.65$ $(\mathrm{dd}, 1 \mathrm{H}, \mathrm{J}=17.4 \mathrm{~Hz}, \mathrm{~J}=10.5 \mathrm{~Hz}) .{ }^{13} \mathrm{C}-\mathrm{NMR}\left(\mathrm{CDCl}_{3}, 100 \mathrm{MHz}\right) \delta 36.2(\mathrm{q}), 127.3$ (d), 128.8 (d), 129.4 (t), 132.6 (d), 143.4 (s), 180.6 (s) HRMS Calcd for $\mathrm{C}_{7} \mathrm{H}_{8} \mathrm{~N}_{2} \mathrm{O}$ 136.0636, found 136.0642 .

\section{Synthesis Diels-Alder products}

The Diels-Alder products were generally obtained as a mixture of endo and exo diastereomers, which were not separated. The NMR data of the endo isomer is presented. In case of $\mathbf{3 c}, \mathbf{3 d}$, and $\mathbf{3 e}$, the $\mathrm{C} 2$ carbon peak of the imidazoles in ${ }^{13} \mathrm{C}$ NMR was too low, and could not be detected.

\section{(1-Methyl-1H-imidazol-2-yl)-(3-phenyl-bicyclo[2.2.1]hept-5-en-2-yl)-methanone} (3a)

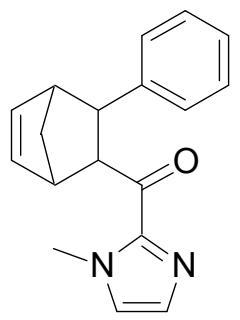

A white solid was obtained after purification by column chromatography $\left(\mathrm{SiO}_{2}, 10 \%\right.$ EtOAc:pentane $) .[\alpha]_{\mathrm{D}}{ }^{20}=+211^{\circ}(\mathrm{c}=0.1$ $\left.\mathrm{CHCl}_{3}\right) ;{ }^{1} \mathrm{H}-\mathrm{NMR}\left(\mathrm{CDCl}_{3}, 400 \mathrm{MHz}\right.$, endo isomer $) \delta 1.59(\mathrm{~d}, 1 \mathrm{H}, \mathrm{J}=$ $8.5 \mathrm{~Hz}), 2.03(\mathrm{~d}, 1 \mathrm{H}, \mathrm{J}=8.5 \mathrm{~Hz}), 3.04(\mathrm{~s}, 1 \mathrm{H}), 3.35(\mathrm{~d}, 1 \mathrm{H}, \mathrm{J}=5.2$ $\mathrm{Hz}), 3.60(\mathrm{~s}, 1 \mathrm{H}), 3.96(\mathrm{~s}, 3 \mathrm{H}), 4.37(\mathrm{~m}, 1 \mathrm{H}), 5.89(\mathrm{dd}, 1 \mathrm{H}, \mathrm{J}=6.6 \mathrm{~Hz}$, $\mathrm{J}=2.8 \mathrm{~Hz}), 6.50(\mathrm{dd}, 1 \mathrm{H}, \mathrm{J}=5.2 \mathrm{~Hz}, \mathrm{~J}=3.2 \mathrm{~Hz}), 7.00(\mathrm{~s}, 1 \mathrm{H}), 7.14-$ $7.17(\mathrm{~m}, 2 \mathrm{H}), 7.24-7.31(\mathrm{~m}, 4 \mathrm{H}) .{ }^{13} \mathrm{C}-\mathrm{NMR}\left(\mathrm{CDCl}_{3}, 400 \mathrm{MHz}\right) \delta$ 45.7 (q), 48.25 (d), 48.28 (d), 49.5 (t), 49.7 (d), 55.1 (d), 125.9 (d), 126.7 (d), 127.6 (d), 128.4 (d), 128.9 (d), 132.8 (d), 139.5 (d), 143.1 (s), 144.2 (s), 192.4 (s). HRMS Calcd for $\mathrm{C}_{18} \mathrm{H}_{18} \mathrm{~N}_{2} \mathrm{O}$ 278.1419, found 278.1420. Anal. Calcd for $\mathrm{C}_{18} \mathrm{H}_{18} \mathrm{~N}_{2} \mathrm{O}$ : C, 77.67 H, 6.52 N, 10.06. Found: C, 77.34 H, 6.58 N, 9.81. Product ratios and e.e.'s were determined by HPLC analysis (Chiralcel-OD, heptane/iPrOH 99:1, $1 \mathrm{ml} / \mathrm{min}$ ). Retention times: 17.5, 20.9 (exo isomer), $19.0(-)$, and $26.2(+)$ mins (endo isomer). 
[3-(4-Methoxy-phenyl)-bicyclo[2.2.1]hept-5-en-2-yl]-(1-methyl-1H-imidazol-2yl)-methanone (3b)<smiles>COc1ccc(C2C3C=CC(C3)C2C(=O)c2nccn2C)cc1</smiles>

A white solid was obtained after purification by column chromatography $\left(\mathrm{SiO}_{2}, \quad 20 \% \quad\right.$ EtOAc:pentane $) .{ }^{1} \mathrm{H}-\mathrm{NMR}$ $\left(\mathrm{CDCl}_{3}, 400 \mathrm{MHz}\right.$, endo isomer) $\delta 1.58(\mathrm{~d}, 1 \mathrm{H}, \mathrm{J}=8.6 \mathrm{~Hz})$, $2.02(\mathrm{~d}, 1 \mathrm{H}, \mathrm{J}=8.5 \mathrm{~Hz}), 2.98(\mathrm{~s}, 1 \mathrm{H}), 3.29(\mathrm{~d}, 1 \mathrm{H}, \mathrm{J}=5.4), 3.59$ $(\mathrm{m}, 1 \mathrm{H}), 3.77(\mathrm{~s}, 3 \mathrm{H}), 3.96(\mathrm{~s}, 3 \mathrm{H}), 4.34(\mathrm{dd}, 1 \mathrm{H}, \mathrm{J}=5.2 \mathrm{~Hz}, \mathrm{~J}=$ $3.5 \mathrm{~Hz}), 5.88(\mathrm{dd}, 1 \mathrm{H}, \mathrm{J}=5.6 \mathrm{~Hz}, \mathrm{~J}=2.7 \mathrm{~Hz}), 6.50(\mathrm{dd}, 1 \mathrm{H}, \mathrm{J}=$ $5.6 \mathrm{~Hz}, \mathrm{~J}=3.1 \mathrm{~Hz}), 6.79-6.83(\mathrm{~m}, 2 \mathrm{H}), 7.00(\mathrm{~s}, 1 \mathrm{H}), 7.14-$ $7.20(\mathrm{~m}, 2 \mathrm{H}), 7.24$ (s, 1H). ${ }^{13} \mathrm{C}-\mathrm{NMR}\left(\mathrm{CDCl}_{3}, 400 \mathrm{MHz}\right) \delta 36.3$ (q), 45.1 (d), $48.2(\mathrm{~d})$, 49.4 (t), 50.0 (d), 55.1 (d), 55.3 (d), 113.8 (d), 126.7 (s), 128.6 (d), 129.0 (d), 132.7 (d), 136.3 (d), 139.5 (d), 143.2 (s), 157.8 (s), 192.6 (s). HRMS Calcd for $\mathrm{C}_{19} \mathrm{H}_{20} \mathrm{~N}_{2} \mathrm{O}_{2}$ 308.1525, found 308.1535. Product ratios and e.e.'s were determined by HPLC analysis (Chiralcel-OD, heptane/iPrOH 98:2, $1 \mathrm{ml} / \mathrm{min}$ ). Retention times: 12.2, 16.6 (exo isomer), 13.4, and 20.8 mins (endo isomer).

\section{[3-(4-Chloro-phenyl)-bicyclo[2.2.1]hept-5-en-2-yl]-(1-methyl-1H-imidazol-2-yl)- methanone (3c)}<smiles>Cn1ccnc1C(=O)C1C2C=CC(C2)C1c1ccc(Cl)cc1</smiles>

A white solid was obtained after purification by column chromatography $\left(\mathrm{SiO}_{2}, 20 \%\right.$ EtOAc:pentane $) .{ }^{1} \mathrm{H}-\mathrm{NMR}\left(\mathrm{CDCl}_{3}\right.$, $400 \mathrm{MHz}$, endo isomer) $\delta 1.53(\mathrm{dd}, 1 \mathrm{H}, \mathrm{J}=8.8 \mathrm{~Hz}, \mathrm{~J}=1.6 \mathrm{~Hz})$, $1.91(\mathrm{~d}, 1 \mathrm{H}, \mathrm{J}=8.5 \mathrm{~Hz}), 2.94(\mathrm{~s}, 1 \mathrm{H}), 3.24(\mathrm{dd}, 1 \mathrm{H}, \mathrm{J}=5.3 \mathrm{~Hz}, \mathrm{~J}=$ $1.7 \mathrm{~Hz}), 3.54$ (s, 1H), $3.90(\mathrm{~s}, 3 \mathrm{H}), 4.24(\mathrm{dd}, 1 \mathrm{H}, \mathrm{J}=5.3 \mathrm{~Hz}, \mathrm{~J}=$ $3.5 \mathrm{~Hz}), 5.93(\mathrm{dd}, 1 \mathrm{H}, \mathrm{J}=5.5 \mathrm{~Hz}, \mathrm{~J}=2.7 \mathrm{~Hz}), 6.53(\mathrm{dd}, 1 \mathrm{H}, \mathrm{J}=$ 5.6, J = 3.1), $6.95(\mathrm{~s}, 1 \mathrm{H}), 7.08(\mathrm{~m}, 1 \mathrm{H}), 7.16(\mathrm{~m}, 4 \mathrm{H}) .{ }^{13} \mathrm{C}-\mathrm{NMR}$ $\left(\mathrm{CDCl}_{3}, 100 \mathrm{MHz}\right) \delta 36.3(\mathrm{q}), 45.2(\mathrm{~d}), 48.2(\mathrm{~d}), 49.5$ (t), 49.6 (d), 55.3 (d), 126.9 (d), 128.4 (d), 129.0 (d), 129.1 (d), 131.6 (s), 132.9 (d), 139.3 (d), 142.8 (s), 192.2 (s). HRMS Calcd for $\mathrm{C}_{18} \mathrm{H}_{17} \mathrm{~N}_{2} \mathrm{OCl} 312.1029$, found 312.1041. Product ratios and e.e.'s were determined by HPLC analysis (Chiralpak-AD, heptane/iPrOH 98:2, $1 \mathrm{ml} / \mathrm{min}$ ). Retention times: 13.8 and 23.5 mins (endo isomer).

\section{[3-(2-Bromo-phenyl)-bicyclo[2.2.1]hept-5-en-2-yl]-(1-methyl-1H-imidazol-2-yl)- methanone (3d)}<smiles>Cn1ccnc1C(=O)C1C2C=CC(C2)C1c1ccccc1Br</smiles>

A white solid was obtained after purification by column chromatography $\left(\mathrm{SiO}_{2}, 20 \%\right.$ EtOAc:pentane $) .{ }^{1} \mathrm{H}-\mathrm{NMR}\left(\mathrm{CDCl}_{3}, 400\right.$ $\mathrm{MHz}$, endo isomer) $\delta 1.57(\mathrm{dd}, 1 \mathrm{H}, \mathrm{J}=8.4 \mathrm{~Hz}, \mathrm{~J}=1.6 \mathrm{~Hz}), 1.95(\mathrm{~d}$, $1 \mathrm{H}, \mathrm{J}=8.6 \mathrm{~Hz}), 3.02(\mathrm{~s}, 1 \mathrm{H}), 3.55(\mathrm{~m}, 2 \mathrm{H}), 3.97(\mathrm{~s}, 3 \mathrm{H}), 4.51(\mathrm{dd}$, $1 \mathrm{H}, \mathrm{J}=5.3 \mathrm{~Hz}, \mathrm{~J}=3.5 \mathrm{~Hz}), 5.95(\mathrm{dd}, 1 \mathrm{H}, \mathrm{J}=5.5 \mathrm{~Hz}, \mathrm{~J}=2.8 \mathrm{~Hz}), 6.55$ $(\mathrm{dd}, 1 \mathrm{H}, \mathrm{J}=5.5 \mathrm{~Hz}, \mathrm{~J}=3.2 \mathrm{~Hz}), 7.01(\mathrm{~s}, 1 \mathrm{H}), 7.04-7.09(\mathrm{~m}, 1 \mathrm{H})$, $7.14(\mathrm{~d}, 1 \mathrm{H}, \mathrm{J}=0.8 \mathrm{~Hz}), 7.23-7.31(\mathrm{~m}, 1 \mathrm{H}), 7.47-7.57(\mathrm{~m}, 2 \mathrm{H})$. ${ }^{13} \mathrm{C}-\mathrm{NMR}\left(\mathrm{CDCl}_{3}, 100 \mathrm{MHz}\right) \delta 36.3(\mathrm{q}), 46.3$ (d), $47.6(\mathrm{~d}), 49.2(\mathrm{t}), 50.2(\mathrm{~d}), 52.3$ (d), 126.2 (s), $126.8(\mathrm{~d}), 127.3$ (d), 127.5 (d), 127.9 (d), 128.9 (d), 133.1 (d), 133.4 (d), 138.7 (d), 143.0 (s), 191.9 (s). HRMS Calcd for $\mathrm{C}_{18} \mathrm{H}_{17} \mathrm{~N}_{2} \mathrm{OBr} 358.0504$, found 358.0522. Product ratios and e.e.'s were determined by HPLC analysis (Chiralpak$\mathrm{AD}$, heptane/iPrOH 99:1, $1 \mathrm{ml} / \mathrm{min}$ ). Retention times: 11.0, 14.1 (exo isomer), 15.9, and 21.0 mins (endo isomer). 

methanone (3e)

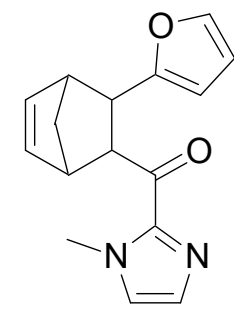

A white solid was obtained after purification by column chromatography $\left(\mathrm{SiO}_{2}, 10 \%\right.$ EtOAc:pentane). ${ }^{1} \mathrm{H}-\mathrm{NMR}\left(\mathrm{CDCl}_{3}, 400\right.$ $\mathrm{MHz}$, endo isomer) $\delta 1.56(\mathrm{~d}, 1 \mathrm{H}, \mathrm{J}=8.8), 1.99(\mathrm{~d}, 1 \mathrm{H}, \mathrm{J}=8.7), 3.05$ $(\mathrm{s}, 1 \mathrm{H}), 3.31(\mathrm{~d}, 1 \mathrm{H}, \mathrm{J}=4.6 \mathrm{~Hz}), 3.59(\mathrm{~s}, 1 \mathrm{H}), 3.96(\mathrm{~s}, 3 \mathrm{H}), 4.41(\mathrm{dd}$, $1 \mathrm{H}, \mathrm{J}=4.2 \mathrm{~Hz}, \mathrm{~J}=3.8 \mathrm{~Hz}), 5.87(\mathrm{dd}, 1 \mathrm{H}, \mathrm{J}=5.3 \mathrm{~Hz}, \mathrm{~J}=2.7 \mathrm{~Hz}), 6.10$ $(\mathrm{d}, 1 \mathrm{H}, \mathrm{J}=2.4 \mathrm{~Hz}), 6.26(\mathrm{~s}, 1 \mathrm{H}), 6.43(\mathrm{dd}, 1 \mathrm{H}, \mathrm{J}=5.1 \mathrm{~Hz}, \mathrm{~J}=3.4 \mathrm{~Hz})$, $7.02(\mathrm{~s}, 1 \mathrm{H}), 7.17(\mathrm{~s}, 1 \mathrm{H}), 7.29(\mathrm{~s}, 1 \mathrm{H}) .{ }^{13} \mathrm{C}-\mathrm{NMR}\left(\mathrm{CDCl}_{3}, 100 \mathrm{MHz}\right)$ $\delta 39.7$ (q), 48.6 (t), 49.0 (d), 49.1 (d), 53.3 (d), 104.8 (d), 110.0 (d), 126.8 (d), 129.0 (d), 132.8 (d), 138.4 (d), 141.1 (d), 157.9 (s), 191.7 (s). HRMS Calcd for $\mathrm{C}_{16} \mathrm{H}_{16} \mathrm{~N}_{2} \mathrm{O}_{2}$ 268.1211, found 268.1208. Product ratios and e.e.'s were determined by HPLC analysis (Chiralcel-OD, heptane/iPrOH 98:2, $1 \mathrm{ml} / \mathrm{min}$ ). Retention times: 8.8, 11.6 (exo isomer), 9.9, and 13.5 mins (endo isomer).

\section{(3-Cyclohexyl-bicyclo[2.2.1]hept-5-en-2-yl)-(1-methyl-1H-imidazol-2-yl)-} methanone (3f)

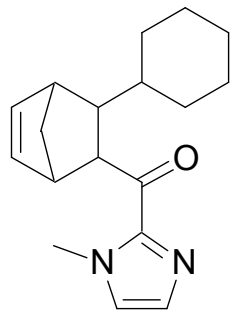

A colourless oil was obtained after column chromatography $\left(\mathrm{SiO}_{2}\right.$, $10 \%$ EtOAc:pentane). ${ }^{1} \mathrm{H}-\mathrm{NMR}\left(\mathrm{CDCl}_{3}, 400 \mathrm{MHz}\right.$, endo isomer) $\delta$ $0.75-1.25(\mathrm{~m}, 6 \mathrm{H}), 1.43(\mathrm{~d}, 1 \mathrm{H}, \mathrm{J}=7.0 \mathrm{~Hz}), 1.59-1.72(\mathrm{~m}, 6 \mathrm{H})$, $1.95(\mathrm{~d}, 1 \mathrm{H}, \mathrm{J}=12.7 \mathrm{~Hz}), 2.88(\mathrm{~s}, 1 \mathrm{H}), 3.34(\mathrm{~s}, 1 \mathrm{H}), 3.92(\mathrm{~s}, 1 \mathrm{H}), 3.95$ $(\mathrm{s}, 3 \mathrm{H}), 5.76(\mathrm{dd}, 1 \mathrm{H}, \mathrm{J}=5.5 \mathrm{~Hz}, \mathrm{~J}=2.7 \mathrm{~Hz}), 6.34(\mathrm{dd}, 1 \mathrm{H}, \mathrm{J}=5.4$ $\mathrm{Hz}, \mathrm{J}=3.3 \mathrm{~Hz}), 7.01(\mathrm{~s}, 1 \mathrm{H}), 7.16(\mathrm{~s}, 1 \mathrm{H}) .{ }^{13} \mathrm{C}-\mathrm{NMR}\left(\mathrm{CDCl}_{3}, 100\right.$ $\mathrm{MHz}) \delta 26.2(\mathrm{t}), 26.6(\mathrm{t}), 32.5(\mathrm{t}), 32.9(\mathrm{~d}), 36.3(\mathrm{q}), 42.2(\mathrm{~d}), 44.6(\mathrm{~d})$, 47.9 (t), 48.7 (d), 52.8 (d), 126.7 (d), 128.8 (d), 131.8 (d), 139.3 (d), 143.1 (s), 193.5 (s). HRMS Calcd for $\mathrm{C}_{18} \mathrm{H}_{16} \mathrm{~N}_{2} \mathrm{O} 284.1889$, found 284.1857. Product ratios and e.e.'s were determined by HPLC analysis (Chiralcel-OD, heptane/iPrOH 99:1, $1 \mathrm{ml} / \mathrm{min}$ ). Retention times: 6.5 (exo isomers), 7.3, and 8.5 mins (endo isomer).

\section{(3-Methyl-bicyclo[2.2.1]hept-5-en-2-yl)-(1-methyl-1H-imidazol-2-yl)-methanone} (3g)<smiles>CC1C2C=CC(C2)C1C(=O)c1nccn1C</smiles>

A colourless oil was obtained after purification by column chromatography $\left(\mathrm{SiO}_{2}, 10 \%\right.$ EtOAc:pentane $) .{ }^{1} \mathrm{H}-\mathrm{NMR}\left(\mathrm{CDCl}_{3}, 400\right.$ $\mathrm{MHz}$, endo isomer) $\delta 1.17(\mathrm{~d}, 3 \mathrm{H}, \mathrm{J}=7.0 \mathrm{~Hz}), 1.46(\mathrm{dd}, 1 \mathrm{H}, \mathrm{J}=8.5 \mathrm{~Hz}$, $\mathrm{J}=1.6 \mathrm{~Hz}), 1.78(\mathrm{~d}, 1 \mathrm{H}, \mathrm{J}=8.5 \mathrm{~Hz}), 2.03(\mathrm{~m}, 1 \mathrm{H}), 2.53(\mathrm{~s}, 1 \mathrm{H}), 3.36(\mathrm{~s}$, $1 \mathrm{H}), 3.74(\mathrm{dd}, 1 \mathrm{H}, \mathrm{J}=3.9 \mathrm{~Hz}, \mathrm{~J}=3.9 \mathrm{~Hz}), 3.95(\mathrm{~s}, 3 \mathrm{H}), 5.81(\mathrm{dd}, 1 \mathrm{H}, \mathrm{J}$ $=5.6 \mathrm{~Hz}, \mathrm{~J}=2.8 \mathrm{~Hz}), 6.34(\mathrm{dd}, 1 \mathrm{H}, \mathrm{J}=5.6 \mathrm{~Hz}, 3.2 \mathrm{~Hz}), 7.00(\mathrm{~s}, 1 \mathrm{H})$, 7.15 (s, 1H). ${ }^{13} \mathrm{C}-\mathrm{NMR}\left(\mathrm{CDCl}_{3}, 100 \mathrm{MHz}\right) \delta 20.6$ (q), 36.0 (q), 36.7 (d), 47.2 (d), 49.1 (t), 49.8 (d), 56.0 (d), 126.6 (d), 128.8 (d), 131.8 (d), 138.8 (d), 143.4 (s), 193.5 (s). HRMS Calcd for $\mathrm{C}_{13} \mathrm{H}_{16} \mathrm{~N}_{2} \mathrm{O}$ 216.1262, found 216.1263. Product ratios and e.e.'s were determined by HPLC analysis (Chiralpakl-AD, heptane/iPrOH 99:1, $1 \mathrm{ml} / \mathrm{min}$ ). Retention times: 7.3, 8.1 (exo isomer), 8.7, and 9.5 mins (endo isomer).

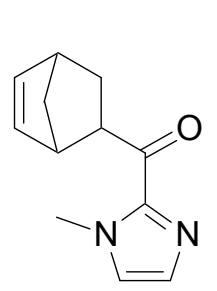

\section{Bicyclo[2.2.1]hept-5-en-2-yl-(1-methyl-1H-imidazol-2-yl)- methanone (3h)}

A colourless oil was obtained after column chromatography $\left(\mathrm{SiO}_{2}, 33 \%\right.$ EtOAc:pentane). ${ }^{1} \mathrm{H}-\mathrm{NMR}\left(\mathrm{CDCl}_{3}, 400 \mathrm{MHz}\right.$, endo isomer) $\delta 1.44-$ $1.51(\mathrm{~m}, 2 \mathrm{H}), 1.53-1.57(\mathrm{~m}, 1 \mathrm{H}), 1.85-1.92(\mathrm{~m}, 1 \mathrm{H}), 2.96(\mathrm{~s}, 1 \mathrm{H})$, $3.44(\mathrm{~s}, 1 \mathrm{H}), 3.94(\mathrm{~s}, 3 \mathrm{H}), 4.20(\mathrm{~m}, 1 \mathrm{H}), 5.80(\mathrm{dd}, 1 \mathrm{H}, \mathrm{J}=5.6 \mathrm{~Hz}, \mathrm{~J}=$ $2.9 \mathrm{~Hz}), 6.24(\mathrm{dd}, 1 \mathrm{H}, \mathrm{J}=5.5 \mathrm{~Hz}, \mathrm{~J}=3.0 \mathrm{~Hz}), 6.99(\mathrm{~s}, 1 \mathrm{H}), 7.15(\mathrm{~s}, 1 \mathrm{H})$. 
${ }^{13} \mathrm{C}-\mathrm{NMR}\left(\mathrm{CDCl}_{3}, 100 \mathrm{MHz}\right) \delta 28.5(\mathrm{t}), 36.2(\mathrm{~d}), 43.2(\mathrm{~d}), 47.4(\mathrm{q}), 48.2(\mathrm{t}), 50.5(\mathrm{~d})$, 126.5 (d), 128.8 (d), 131.4 (d) 137.7 (d), 143.4 (s), 193.5 (s). HRMS Calcd for $\mathrm{C}_{12} \mathrm{H}_{14} \mathrm{~N}_{2} \mathrm{O}$ 202.1106, found 202.1111. Product ratios and e.e.'s were determined by HPLC analysis (Chiralcel-OD, heptane/iPrOH 99.3:0.7, $1 \mathrm{ml} / \mathrm{min}$ ). Retention times: 10.1 (exo isomers), 11.7, and 12.6 mins (endo isomer).

$\mathrm{Cu}(\mathrm{L} 7)\left(\mathrm{NO}_{3}\right)_{2} / \mathrm{DNA}$ catalyzed Diels-Alder cycloaddition on a $1.0 \mathrm{mmol}$ scale. In a $500 \mathrm{~mL}$ Schott bottle was added $19 \mathrm{mg} \mathrm{Cu}(\mathbf{L} 7)\left(\mathrm{NO}_{3}\right)_{2}(0.050 \mathrm{mmol}), 166 \mathrm{~mL}$ water, and $333 \mathrm{~mL}$ of a salmon testes DNA solution $(2 \mathrm{mg} / \mathrm{mL}$ in $30 \mathrm{mM}$ MOPS buffer, $\mathrm{pH} 6.5$; prepared $24 \mathrm{~h}$ in advance), respectively. After cooling for an hour at 0 ${ }^{\circ} \mathrm{C}$, $1 \mathrm{a}(212 \mathrm{mg}, 1.0 \mathrm{mmol}$, in $2 \mathrm{~mL}$ DMSO) was added, and the reaction was started by addition of $0.67 \mathrm{~mL}$ cyclopentadiene $(7.0 \mathrm{mmol})$. The reaction was mixed for three days by continouos inversion. The reaction mixture was extracted with EtOAc, dried on $\mathrm{Na}_{2} \mathrm{SO}_{4}$ and concentrated. Purification by column chromatography yielded $\mathbf{3 a}$ as a white crystalline powder (194 mg, 70\% yield).

\section{3-Phenyl-bicyclo[2.2.1]hept-5-ene-2-carboxylic acid methyl ester}<smiles>COC(=O)C1C2C=CC(C2)C1c1ccccc1</smiles>
(6)

To a 2 dram oven dried vial under $\mathrm{N}_{2}$ atmosphere was added 3a (24 $\mathrm{mg}, 0.09 \mathrm{mmol})$, powdered $4 \AA \mathrm{mol}$. sieves $(10 \mathrm{mg})$ and acetonitrile $(0.6 \mathrm{~mL})$. The mixture was stirred at room temperature and methyl triflate $(11 \mu \mathrm{L}, 0.1 \mathrm{mmol})$ was added. After stirring for $3 \mathrm{~h}, \mathrm{MeOH}$ $(0.6 \mathrm{~mL})$ and DBU $(0.15 \mathrm{~mL})$ were added. The mixture was stirred for another 20 minutes and then diluted with $30 \mathrm{~mL}$ EtOAc. This was washed with bicarbonate and brine, dried on sodium sulfate and subsequently concentrated. Column chromagraphy ( $\mathrm{SiO}_{2}, 1: 25$ EtOAc:pentane) provided 4 as a colourless oil (8.0 $\mathrm{mg}, 41 \%)$. The NMR spectrum was as published. ${ }^{6}$

\section{References}

1. G. Roelfes, B. L. Feringa, Angew. Chem. Int. Ed., 2005, 44, 3230-3232.

2. G. Roelfes, A. J. Boersma, B. L. Feringa, Chem. Commun., 2006, 635-637.

3. S. Otto, J. B. F. N. Engberts, J. Am. Chem. Soc., 1999, 121, 6798-6806.

4. D. A. Evans, K. R. Fandrick, H.-J. Song, J. Am. Chem. Soc., 2005, 127, 89428943.

5. M. C. Myers, A. R. Bharadwaj, B. C. Milgram, K. A. Scheidt, J. Am. Chem. Soc., 2005, 127, 14675-14680.

6. Y. Arai, T. Masuda, Y. Masaki, J. Chem. Soc., Perkin Trans. 1, 1999, 67986806. 


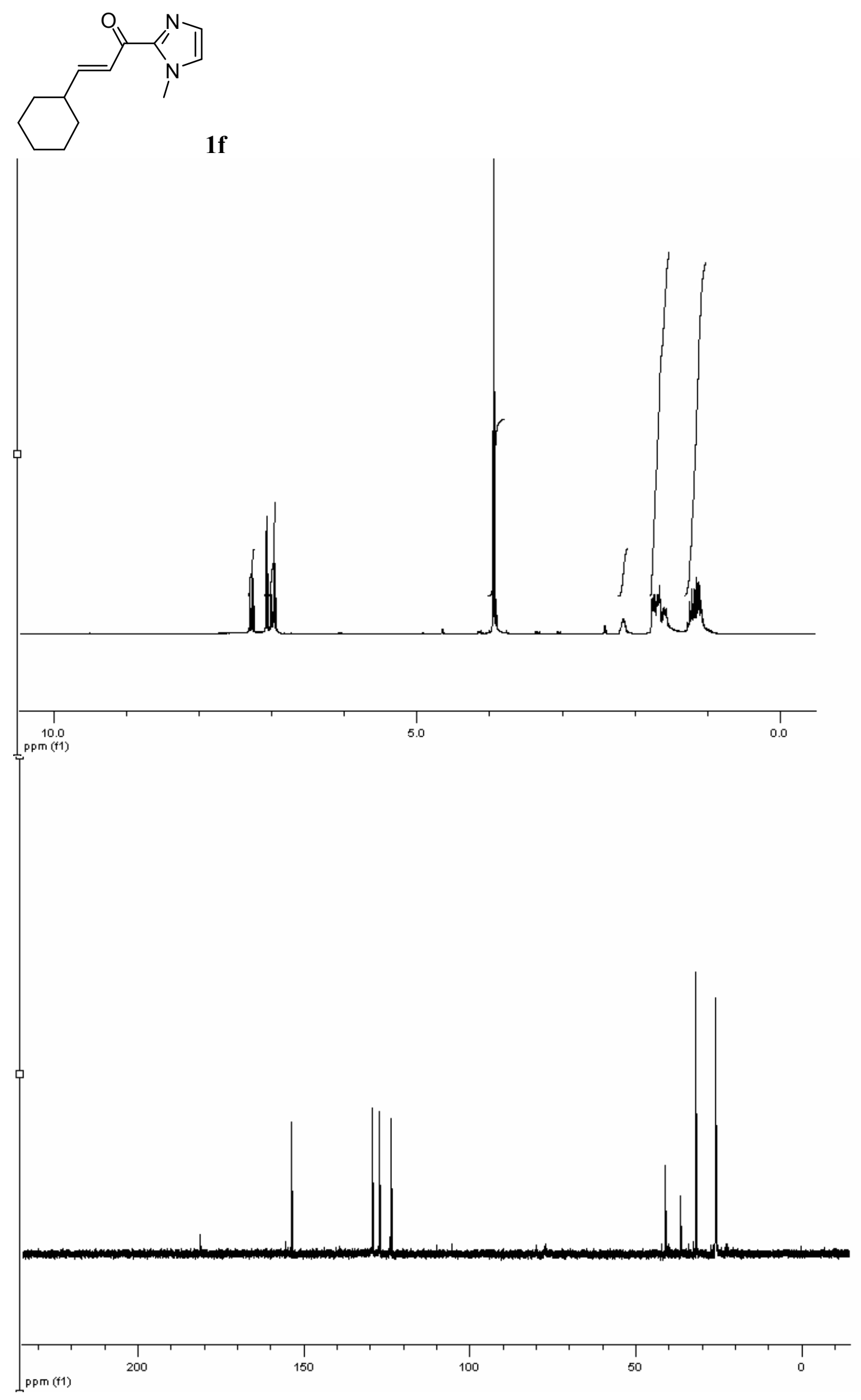


$=\sum_{N}^{\mathrm{N}}$

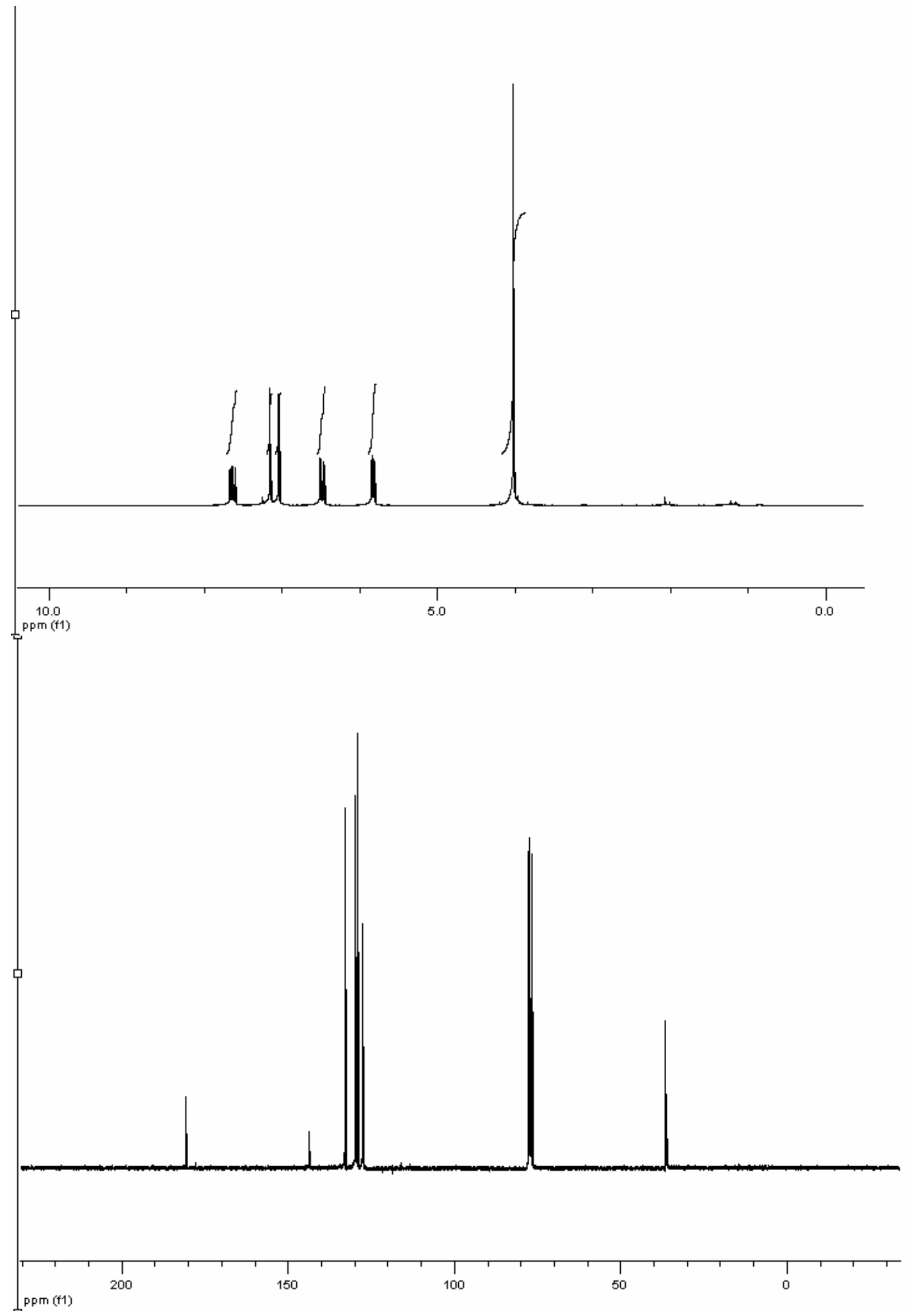



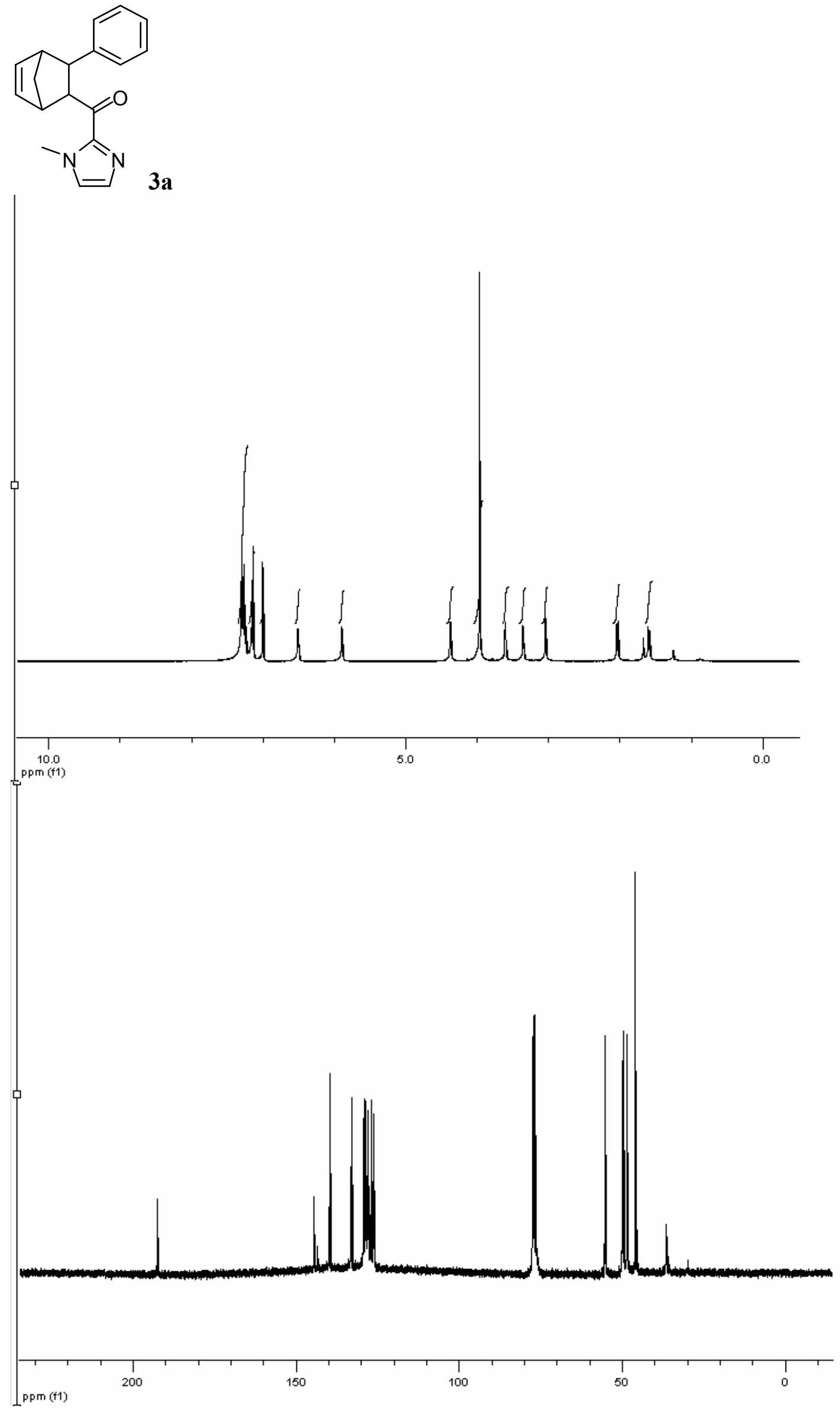
HPLC analysis of 3a (Chiralcel-OD, heptane/iPrOH 99:1, $1 \mathrm{ml} / \mathrm{min}$. Retention times: 17.5, 20.9 (exo isomer), $19.0(-)$, and $26.2(+)$ mins (endo isomer).

Racemic 3a:

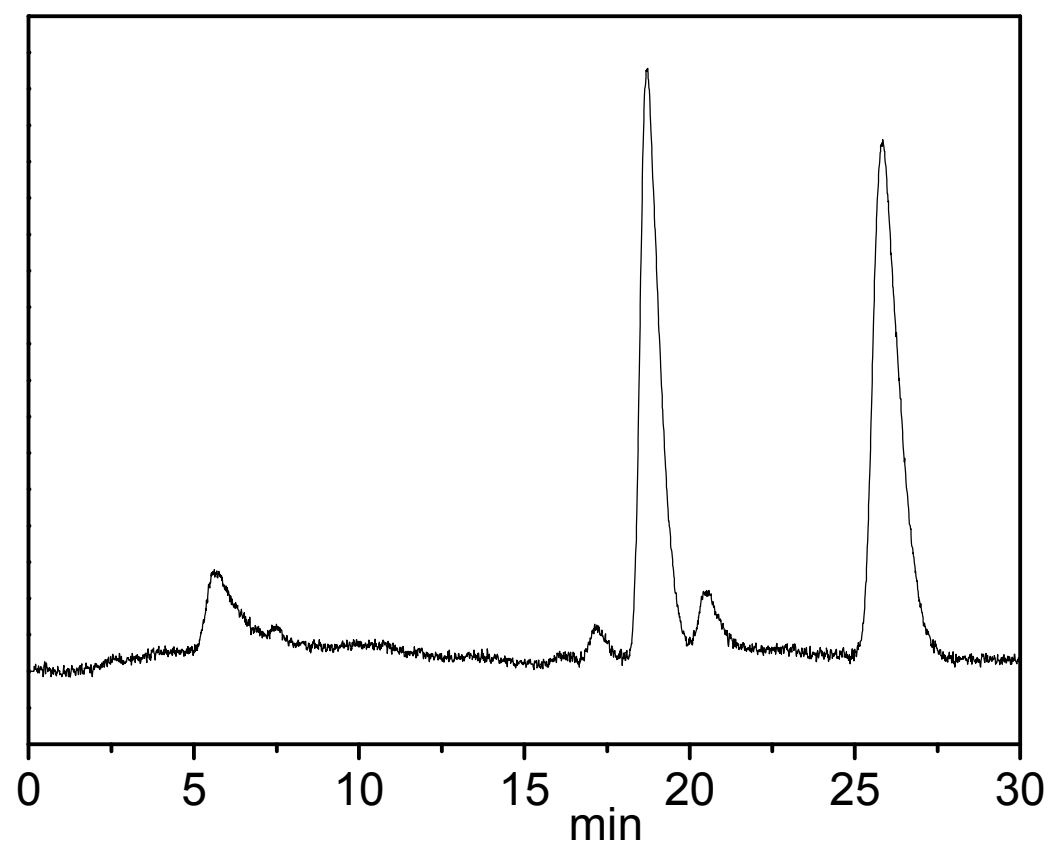

Enantiomerically enriched 3a from $\mathrm{Cu}-\mathrm{L} 7 / \mathrm{st}-\mathrm{DNA}$ catalyzed reaction:

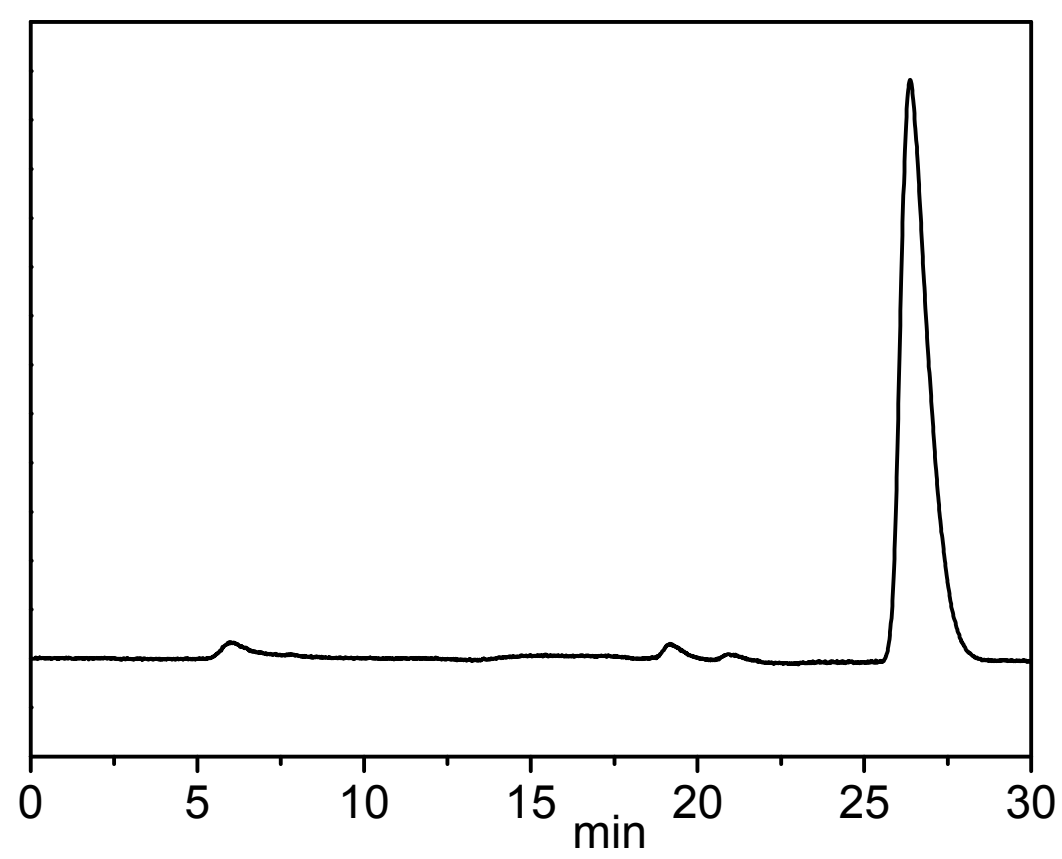



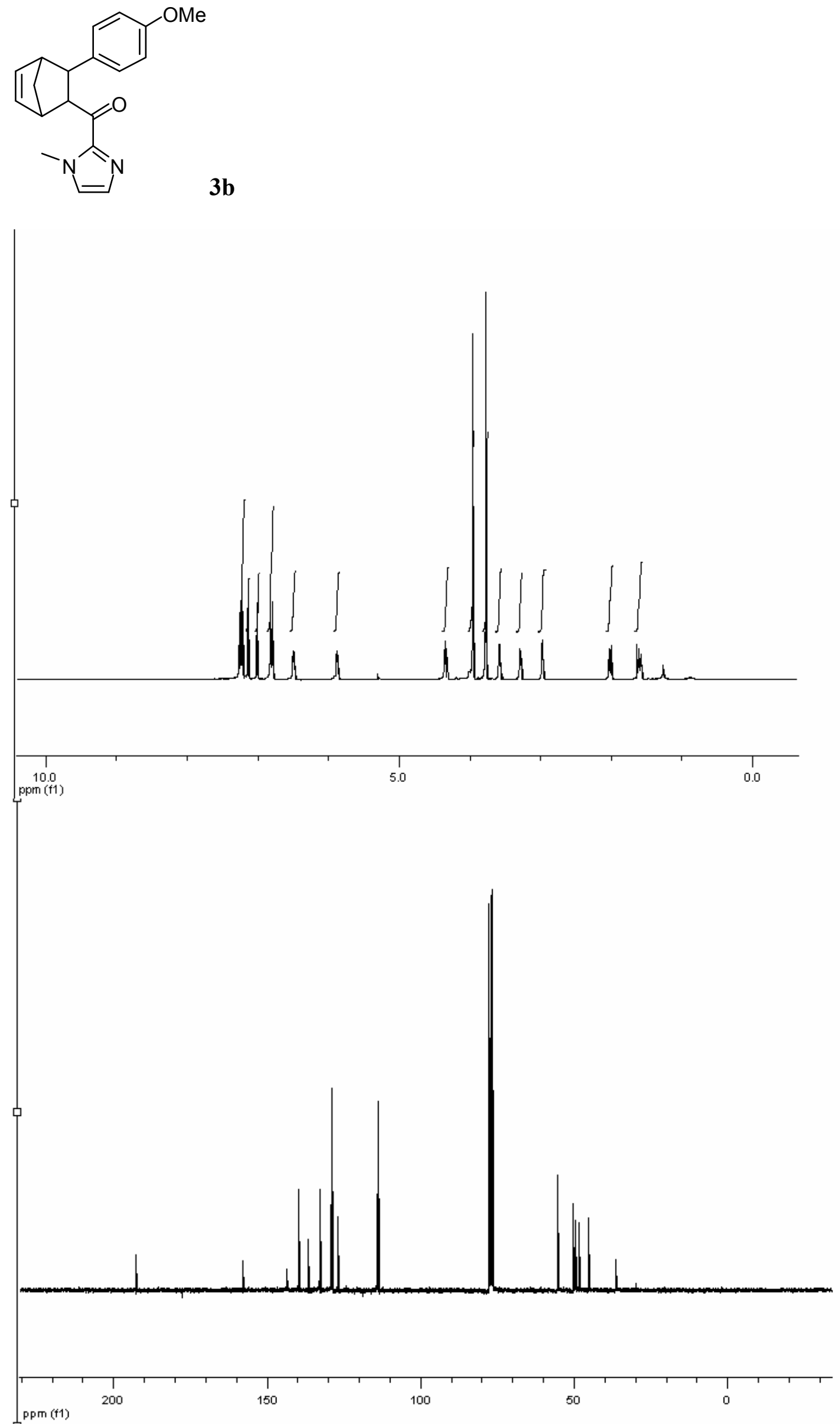
HPLC analysis of $\mathbf{3 b}$ (Chiralcel-OD, heptane/iPrOH 98:2, $1 \mathrm{ml} / \mathrm{min}$. Retention times: 12.2, 16.6 (exo isomer), 13.4, and 20.8 mins (endo isomer).

Racemic 3b:

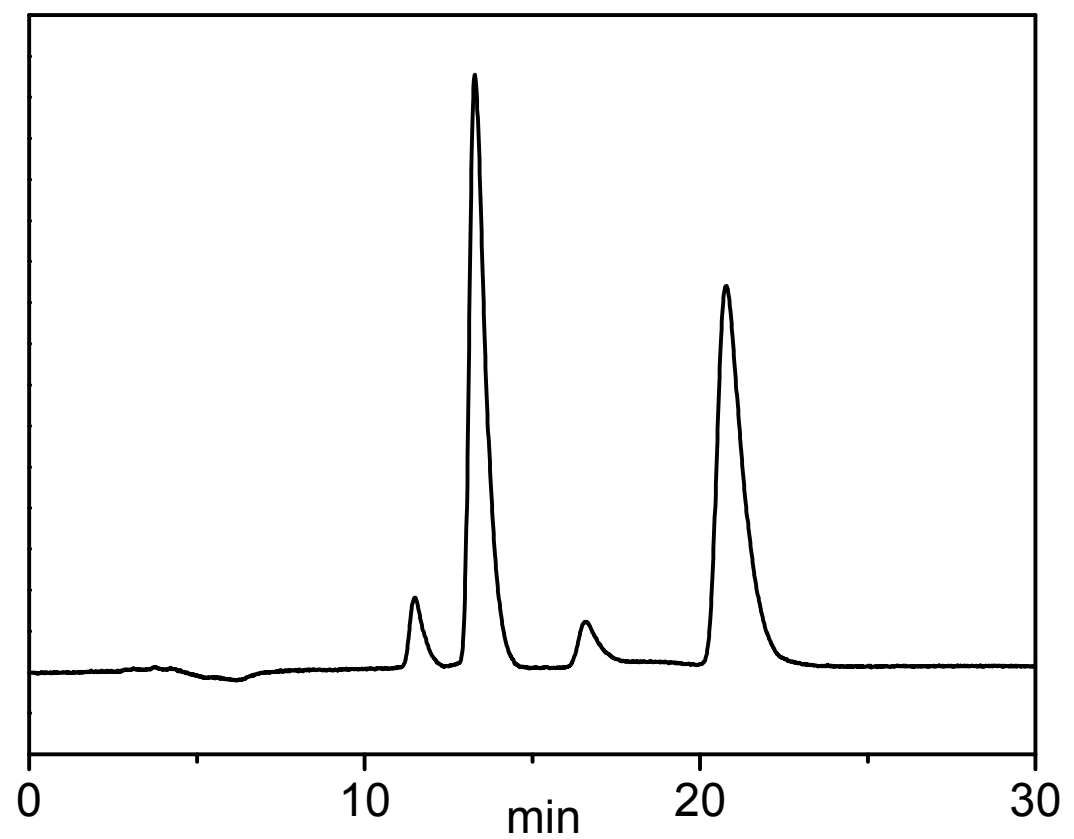

Enantiomerically enriched $\mathbf{3 b}$ from $\mathrm{Cu}-\mathrm{L} 7 /$ st-DNA catalyzed reaction:

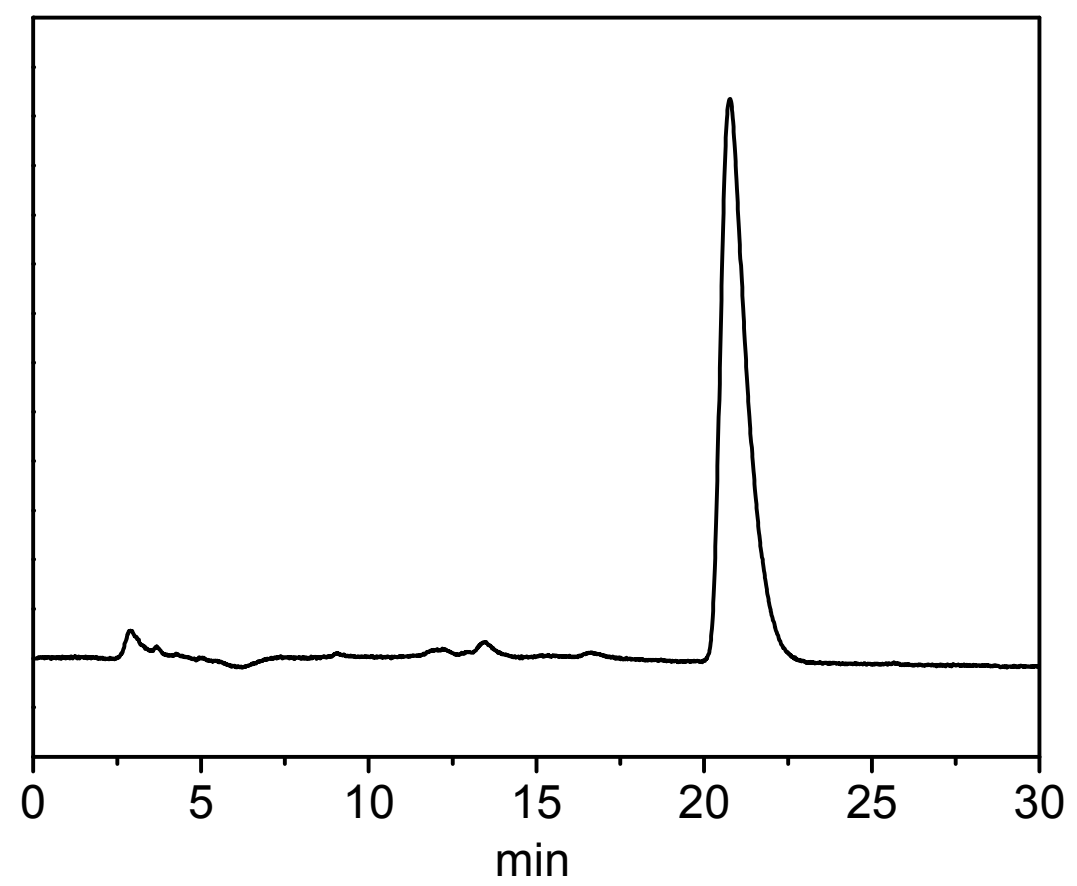



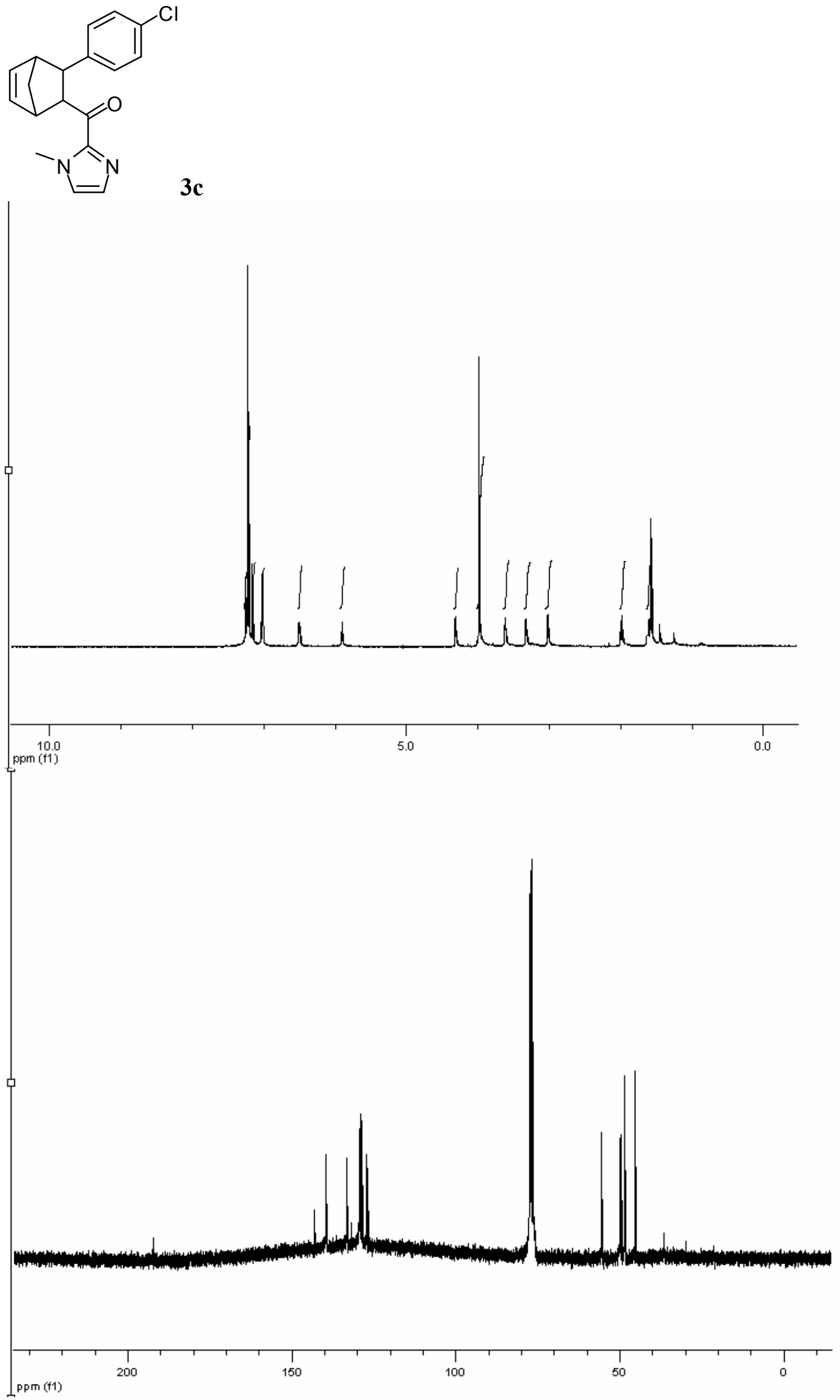

S12 
HPLC analysis of 3c (Chiralpak-AD, heptane/iPrOH 98:2, $1 \mathrm{ml} / \mathrm{min}$. Retention times: 13.8 and 23.5 mins (endo isomer).

Racemic 3c:

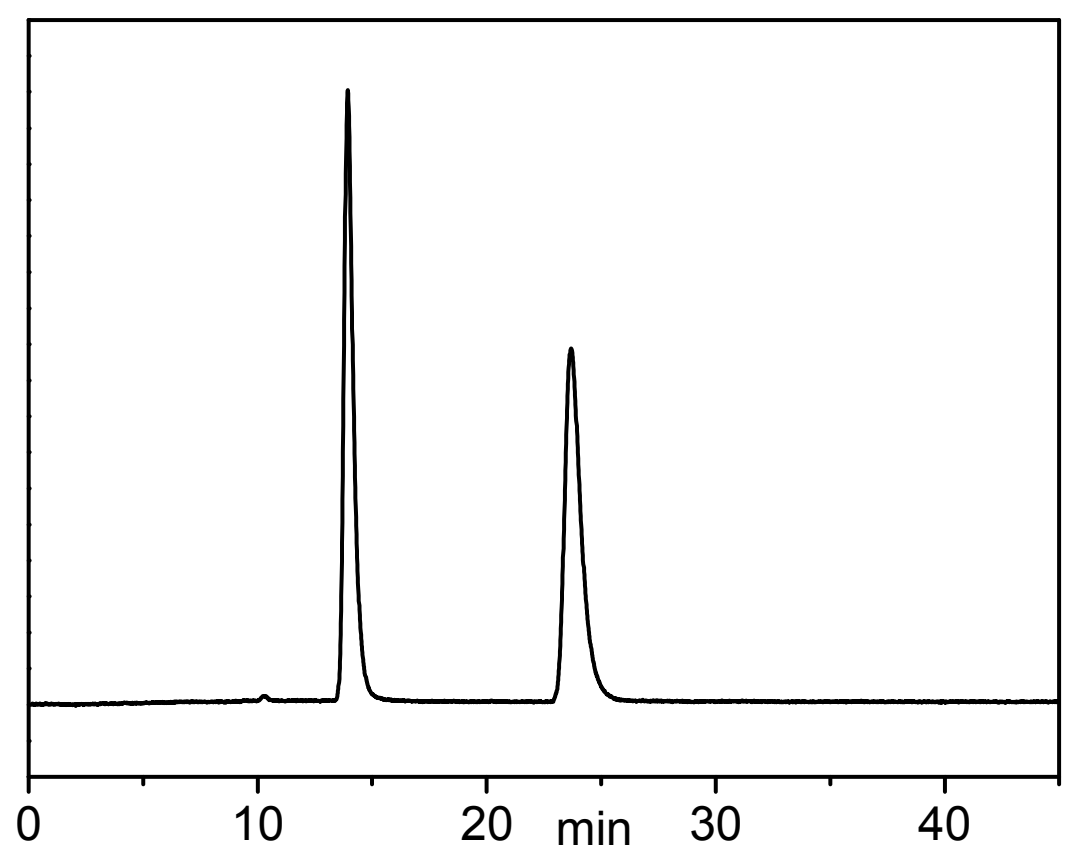

Enantiomerically enriched $\mathbf{3 c}$ from $\mathrm{Cu}-\mathrm{L} 7 /$ st-DNA catalyzed reaction:

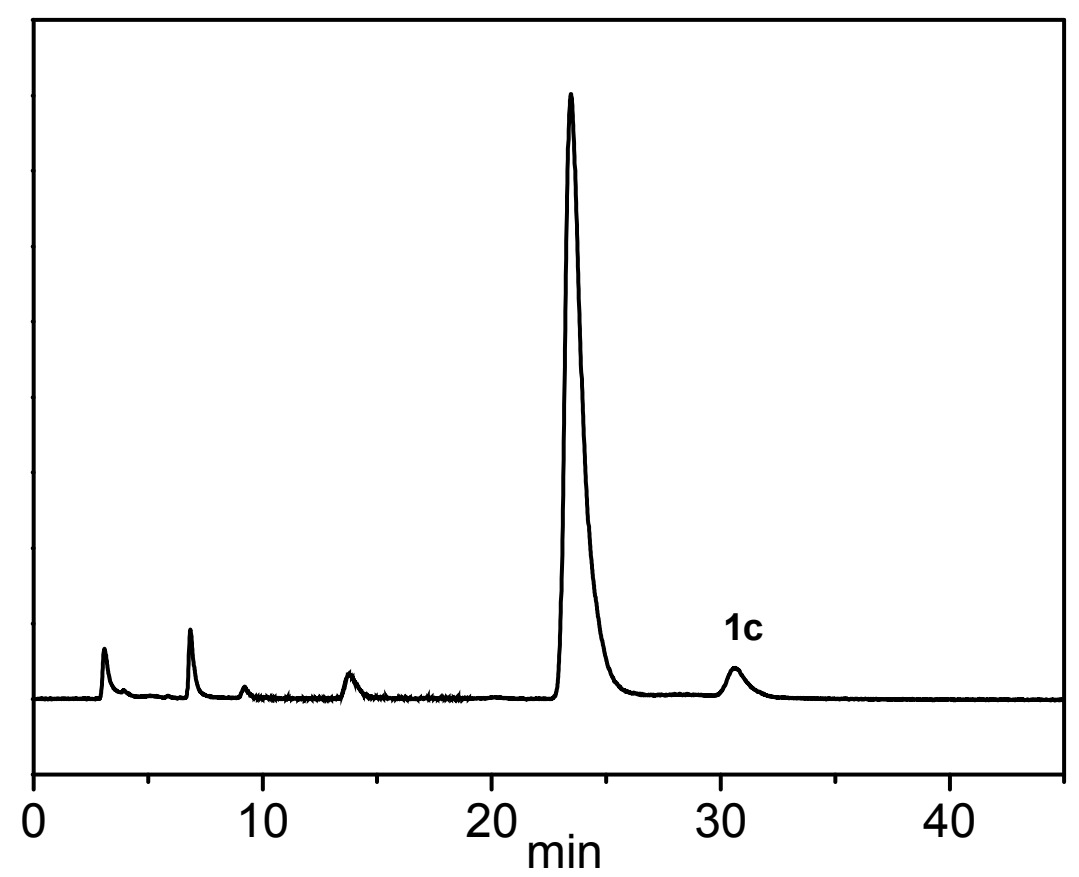



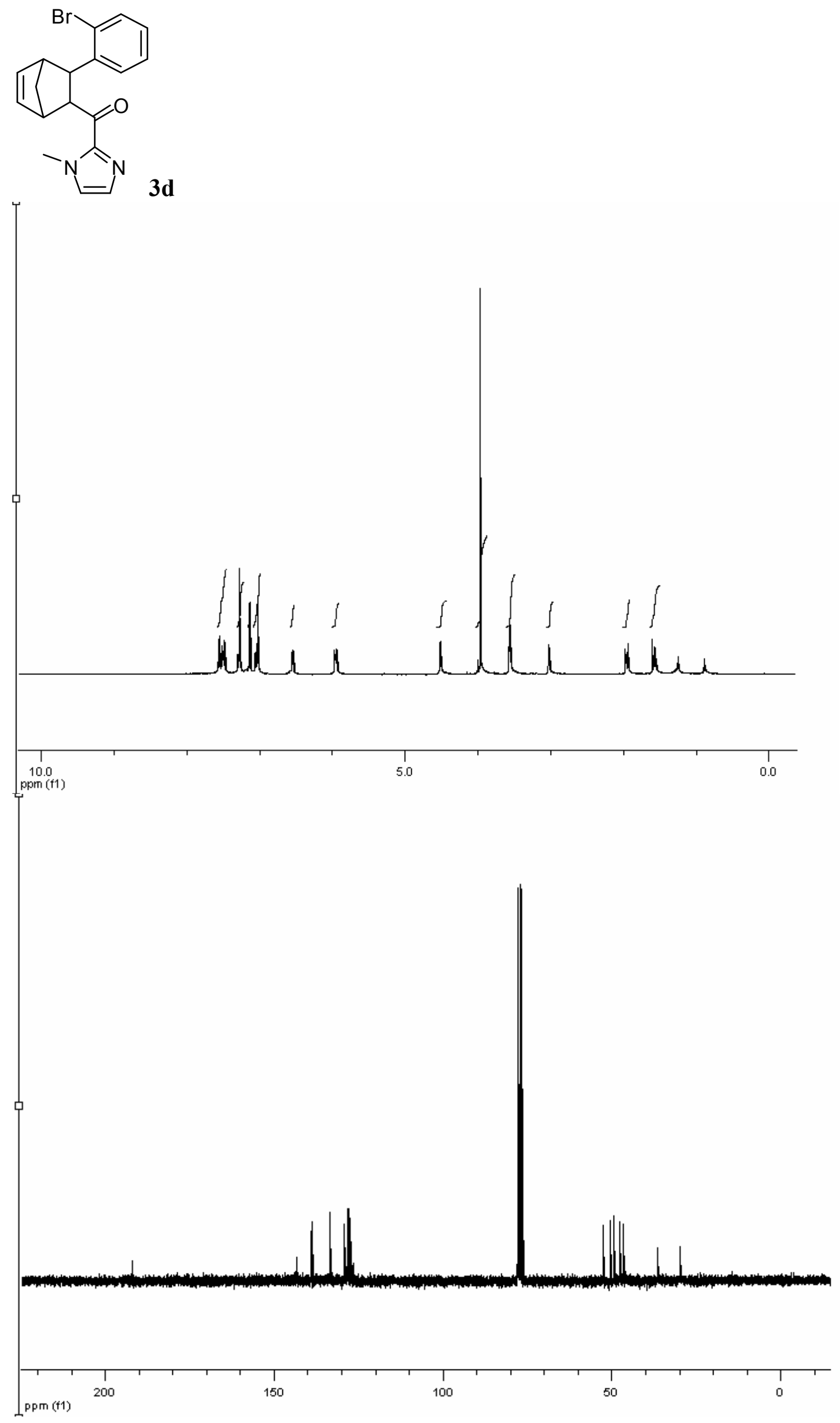
HPLC analysis of 3d (Chiralpak-AD, heptane/iPrOH 99:1, $1 \mathrm{ml} / \mathrm{min}$ ). Retention times: 11.0, 14.1 (exo isomer), 15.9, and 21.0 mins (endo isomer).

Racemic 3d:

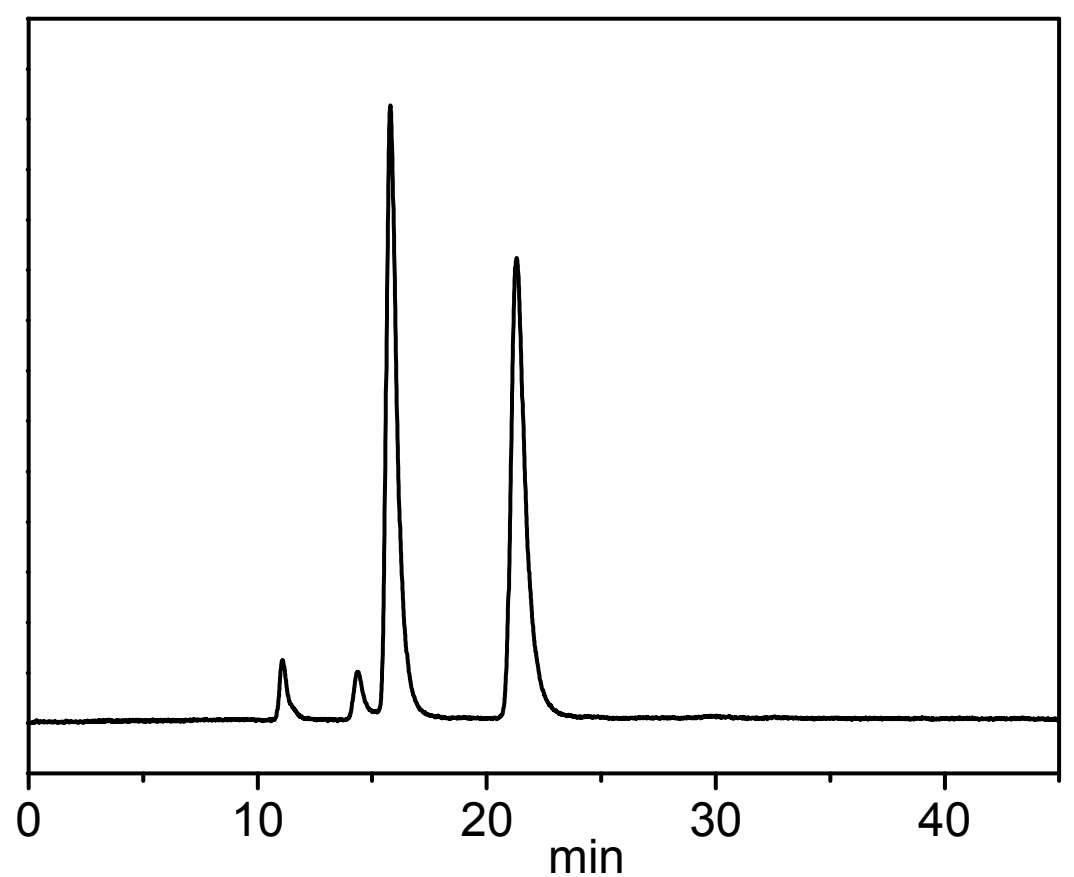

Enantiomerically enriched 3d from $\mathrm{Cu}-\mathrm{L} 7 /$ st-DNA catalyzed reaction:

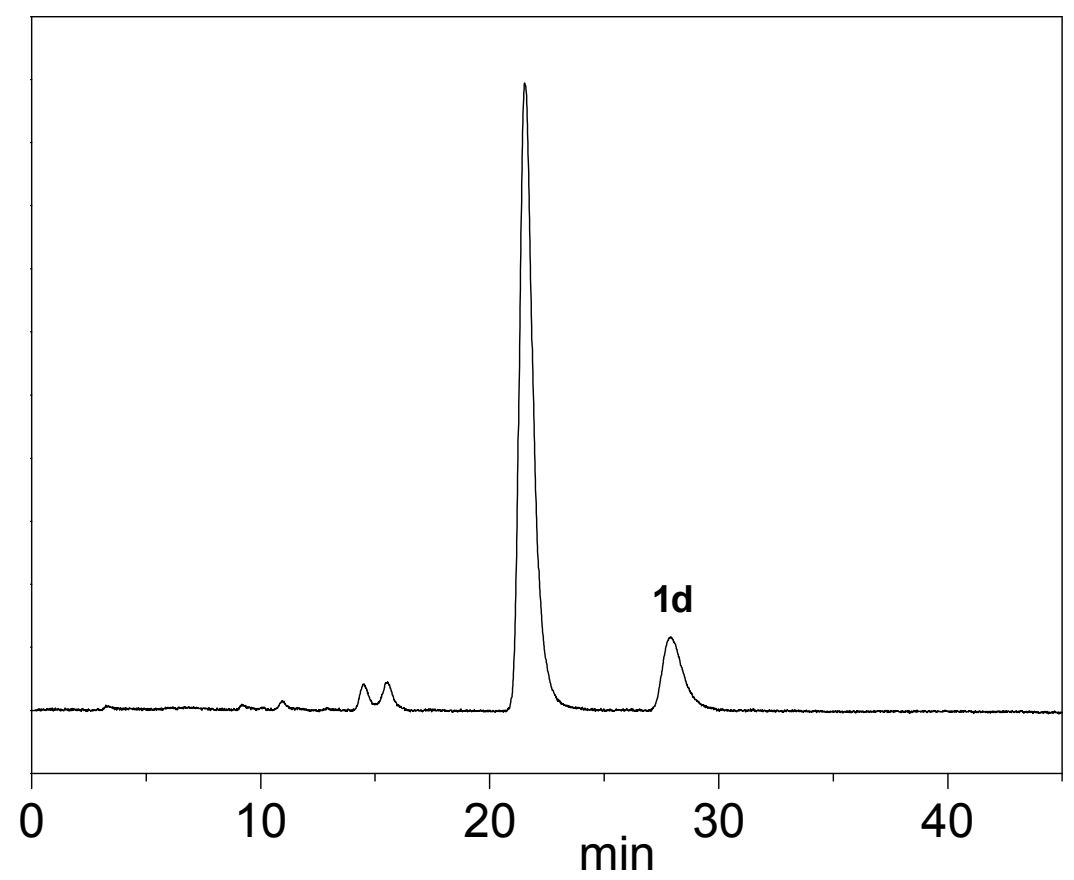




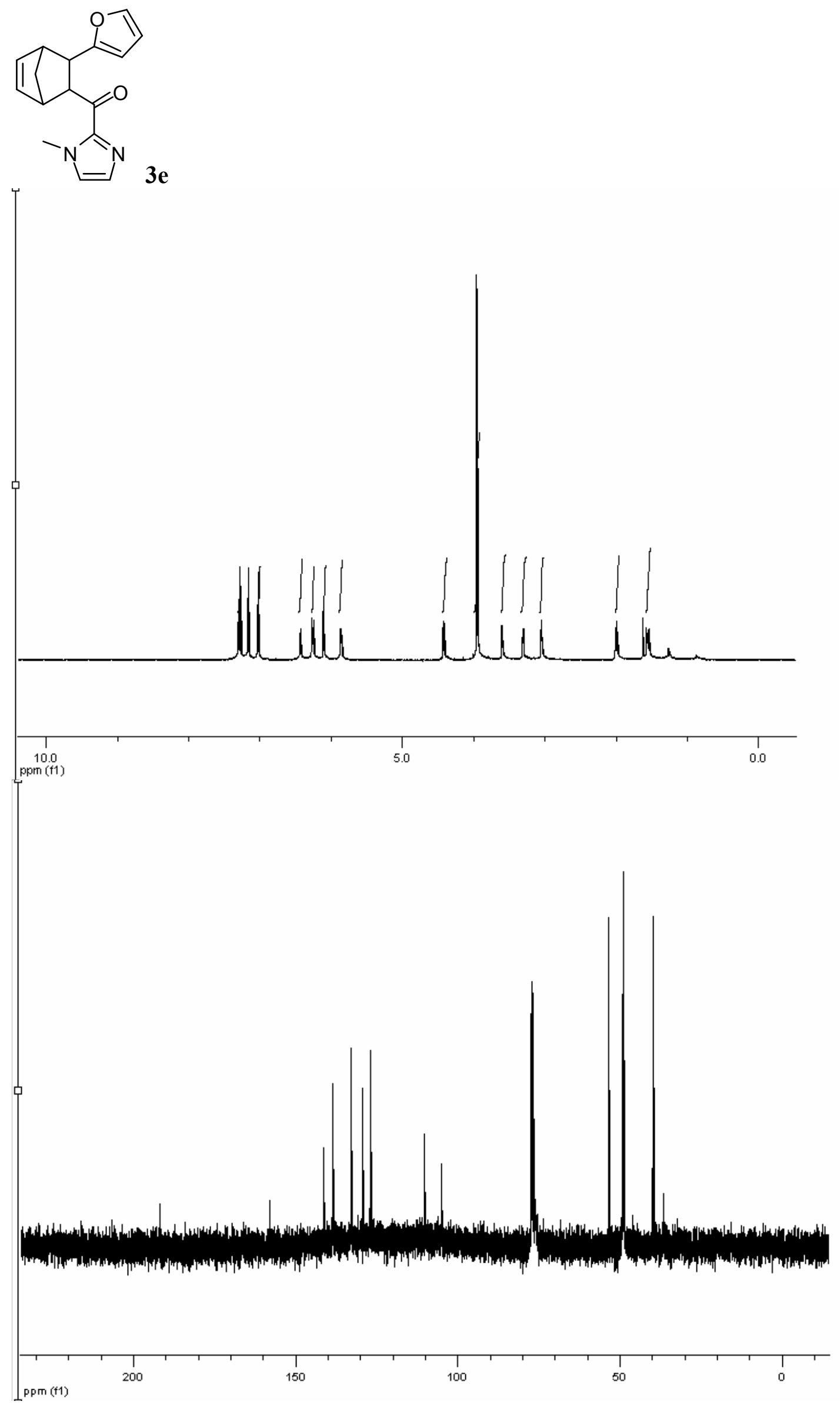


HPLC analysis of 3e (Chiralcel-OD, heptane/iPrOH 98:2, $1 \mathrm{ml} / \mathrm{min})$. Retention times: 8.8, 11.6 (exo isomer), 9.9, and 13.5 mins (endo isomer).

Racemic 3e:

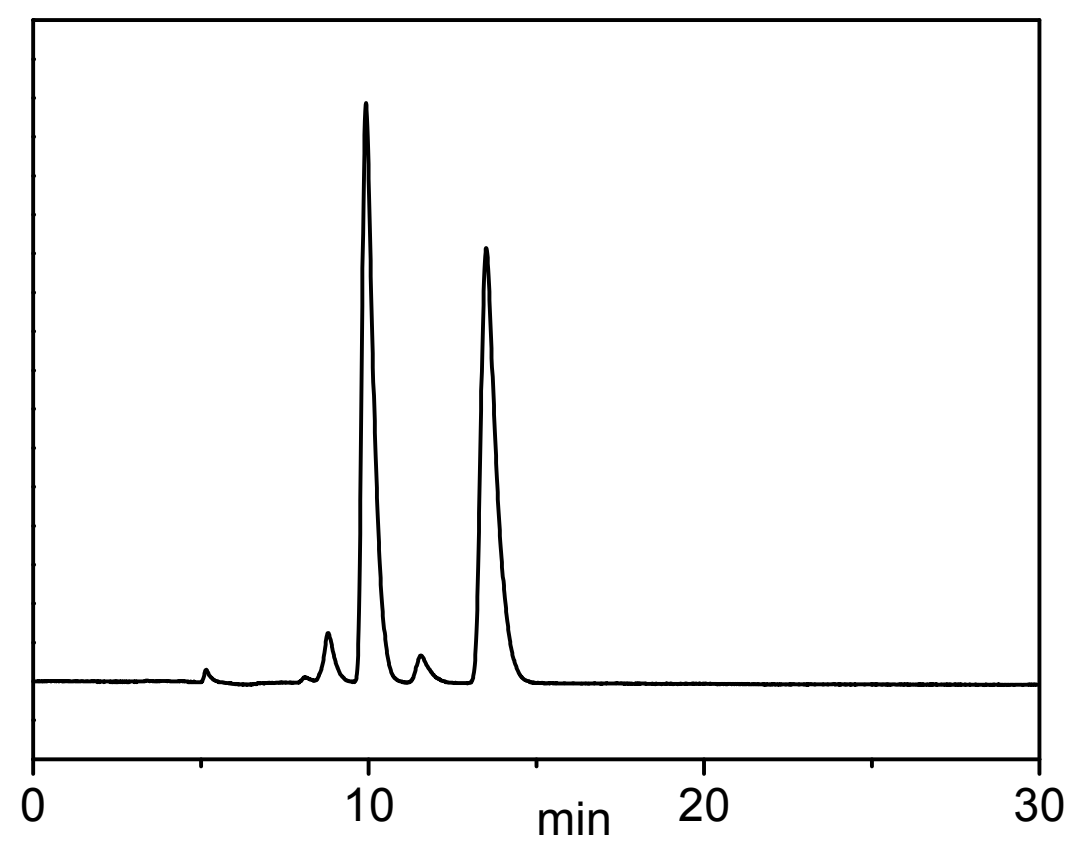

Enantiomerically enriched $3 \mathbf{e}$ from $\mathrm{Cu}-\mathrm{L} 7 / \mathrm{st}-\mathrm{DNA}$ catalyzed reaction:

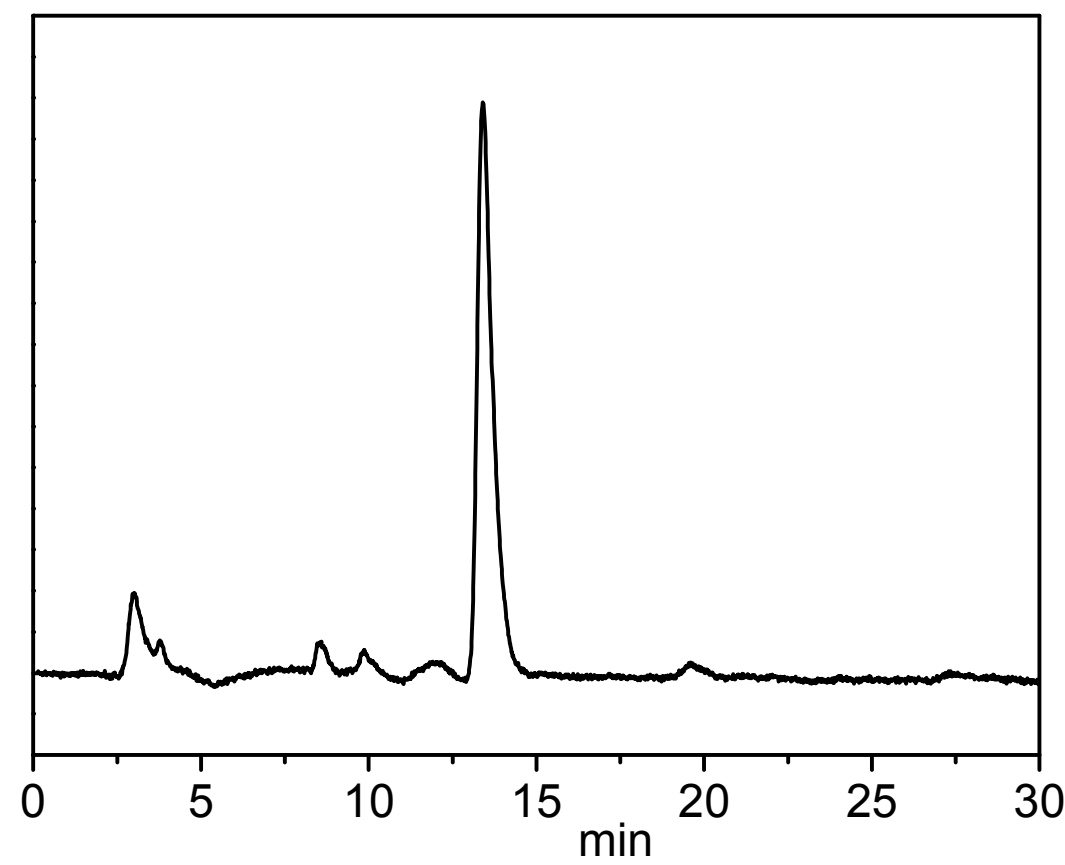



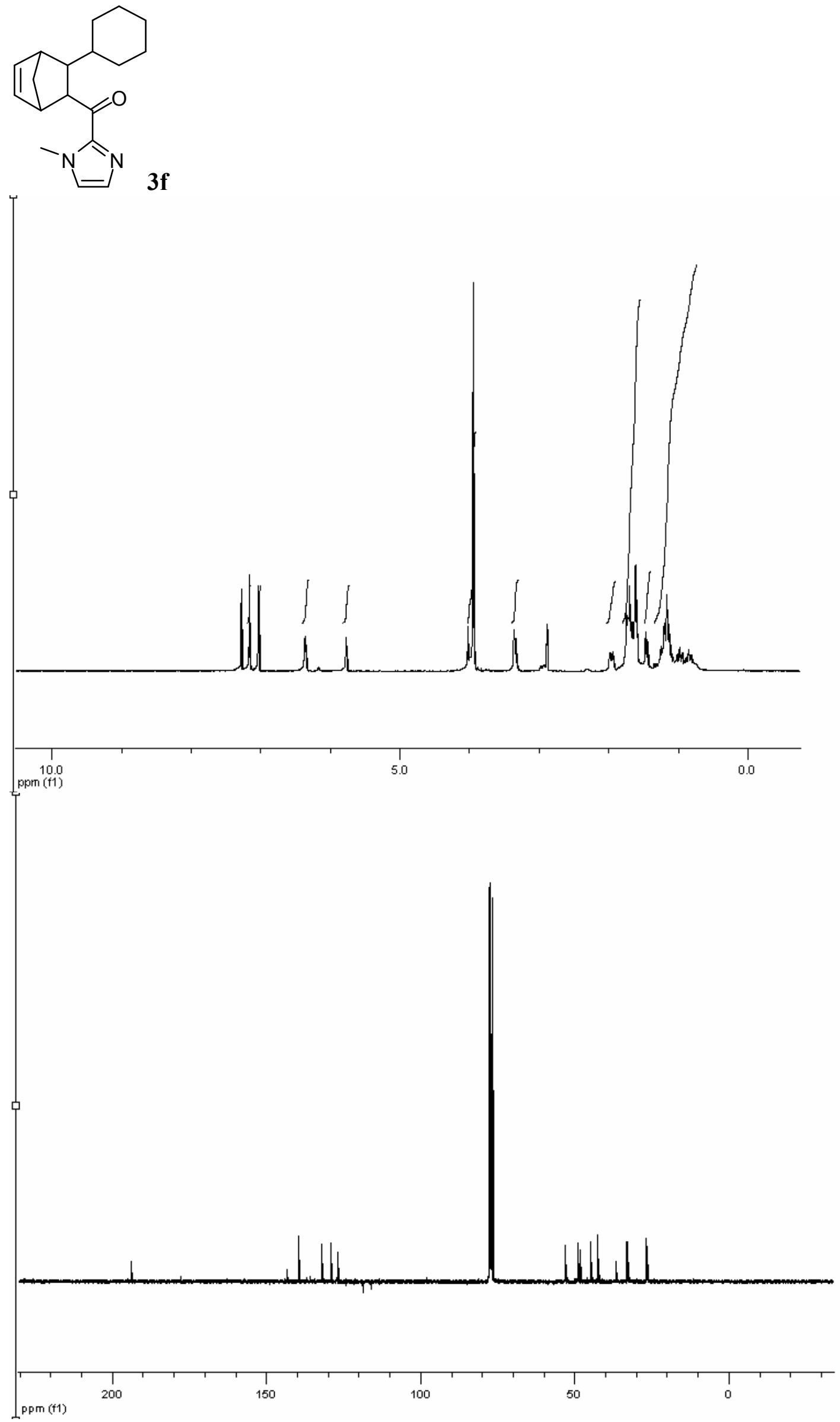
HPLC analysis of $\mathbf{3 f}$ (Chiralcel-OD, heptane/iPrOH 99:1, $1 \mathrm{ml} / \mathrm{min})$. Retention times: 6.5 (exo isomers), 7.3, and 8.5 mins (endo isomer).

Racemic 3f:

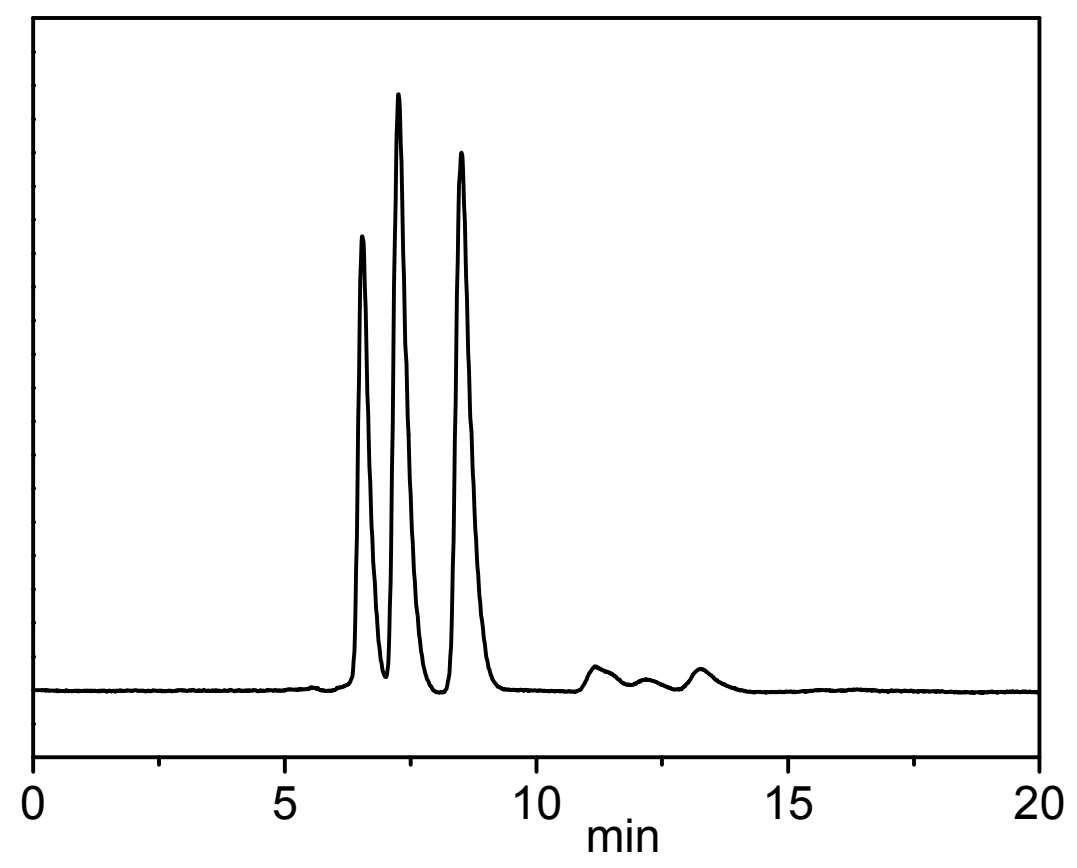

Enantiomerically enriched $\mathbf{3 f}$ from $\mathrm{Cu}-\mathrm{L} 7 /$ st-DNA catalyzed reaction:

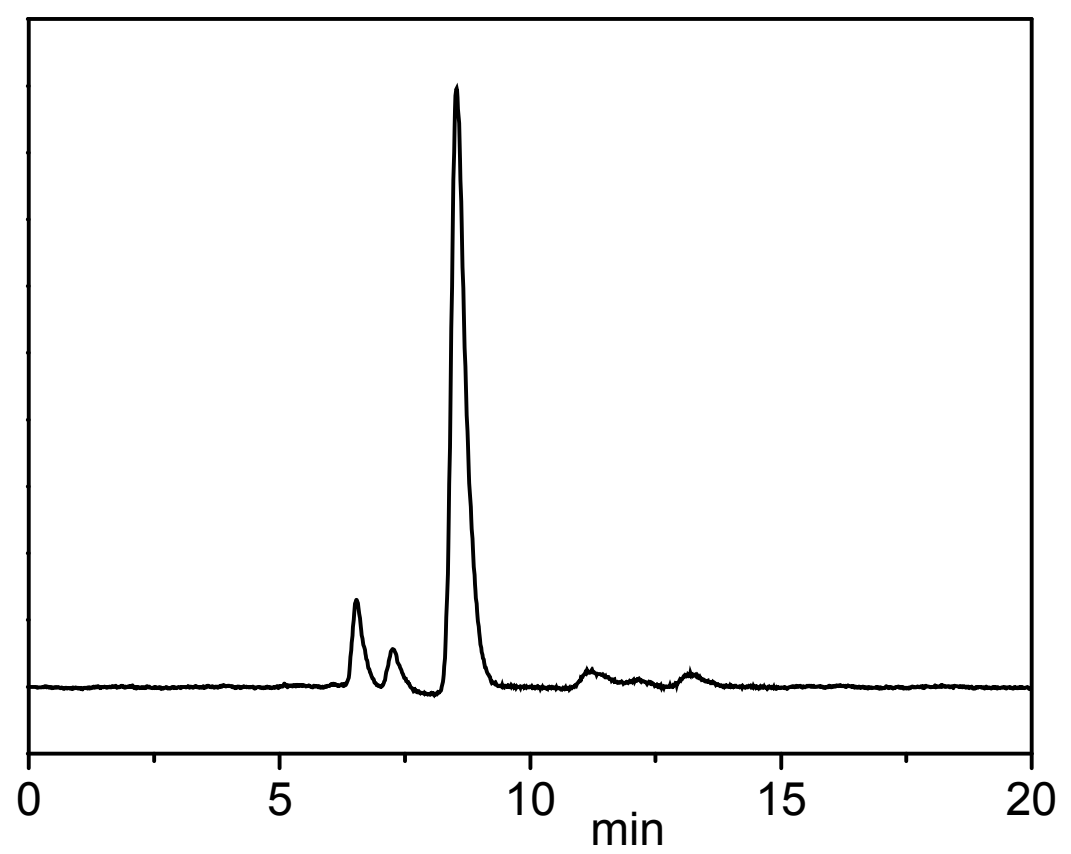



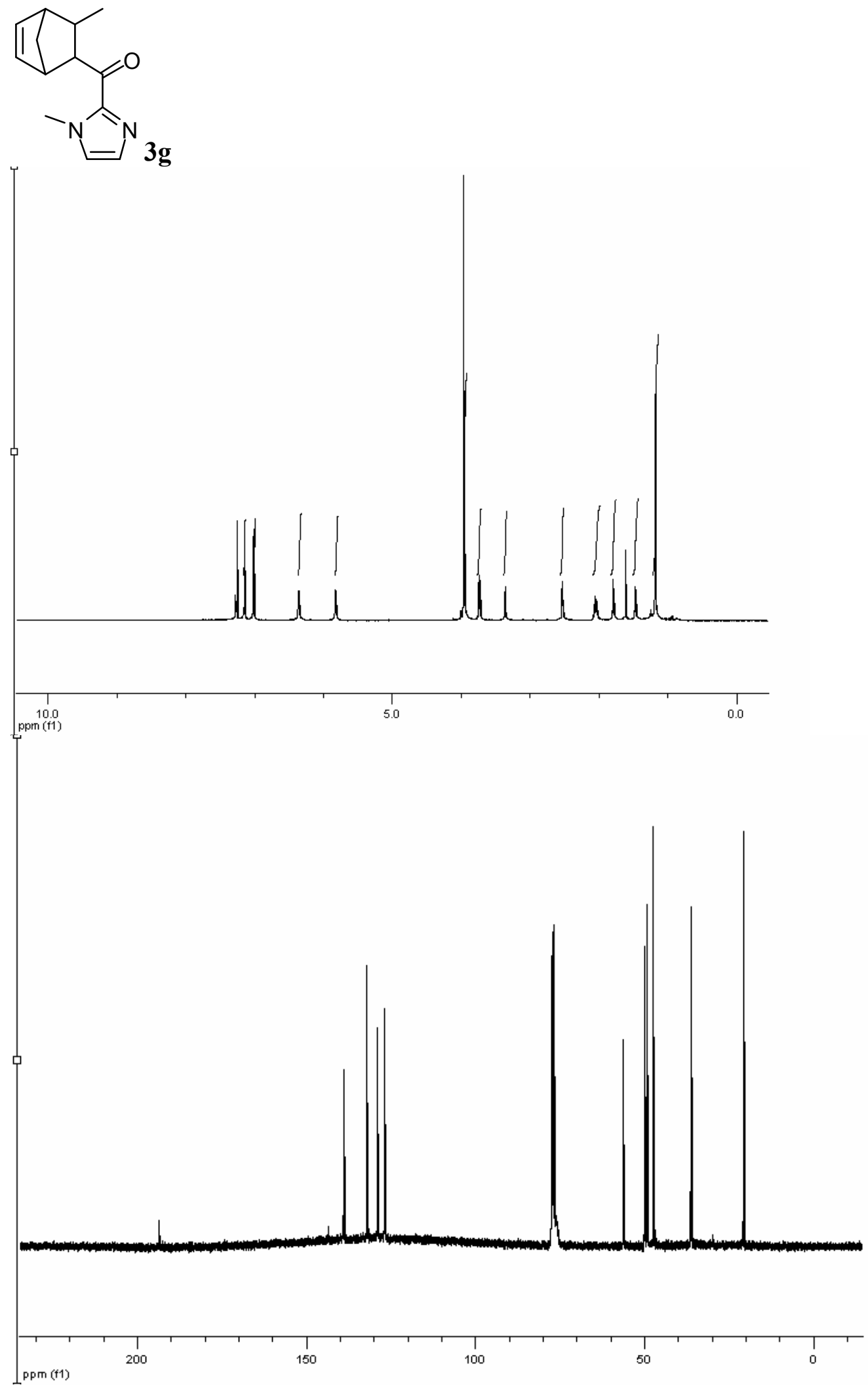
HPLC analysis of $\mathbf{3 g}$ (Chiralpakl-AD, heptane/iPrOH 99:1, $1 \mathrm{ml} / \mathrm{min}$ ). Retention times: 7.3, 8.1 (exo isomer), 8.7, and 9.5 mins (endo isomer).

\section{Racemic 3g:}

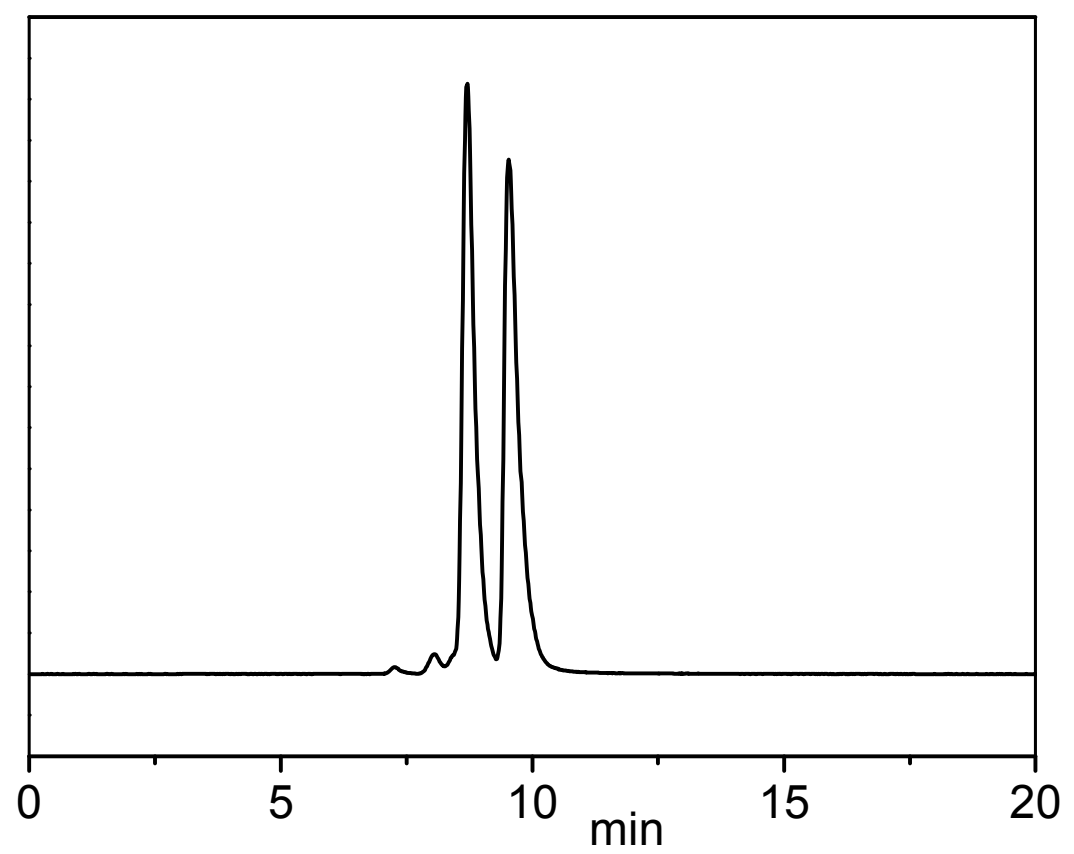

Enantiomerically enriched $\mathbf{3 g}$ from $\mathrm{Cu}-\mathrm{L} 7 / \mathrm{st}-\mathrm{DNA}$ catalyzed reaction:

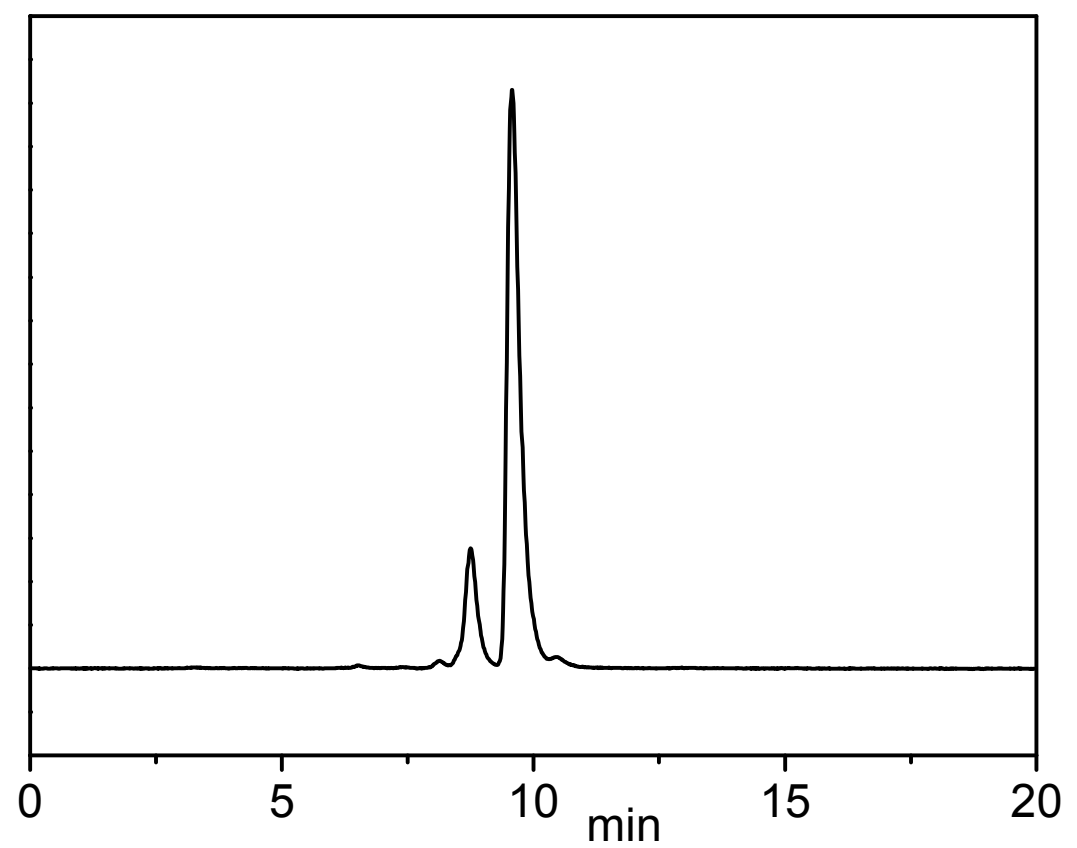



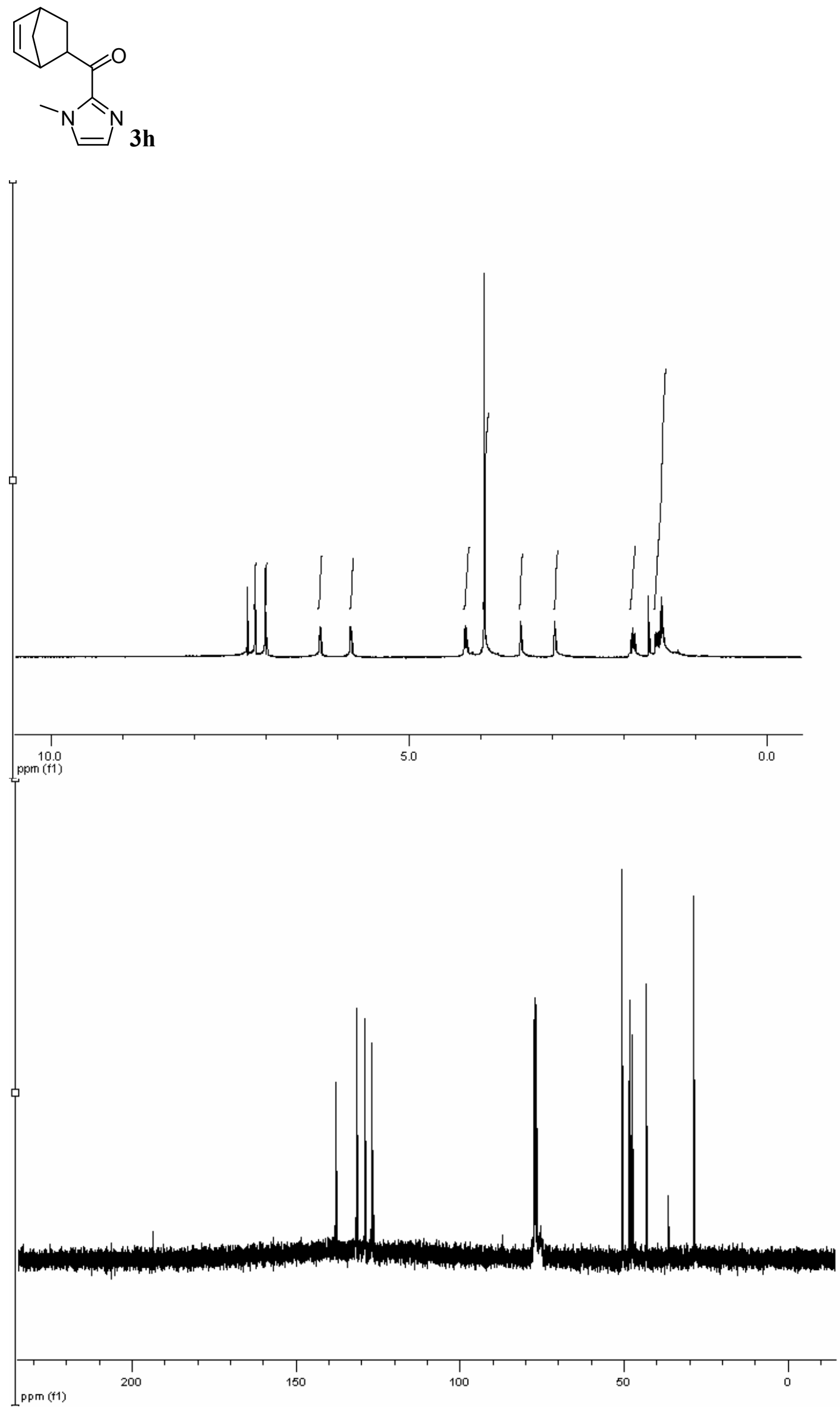
HPLC analysis of $\mathbf{3 h}$ (Chiralcel-OD, heptane/iPrOH 99.3:0.7, $1 \mathrm{ml} / \mathrm{min}$ ). Retention times: 10.1 (exo isomers), 11.7, and 12.6 mins (endo isomer).

Racemic 3h:

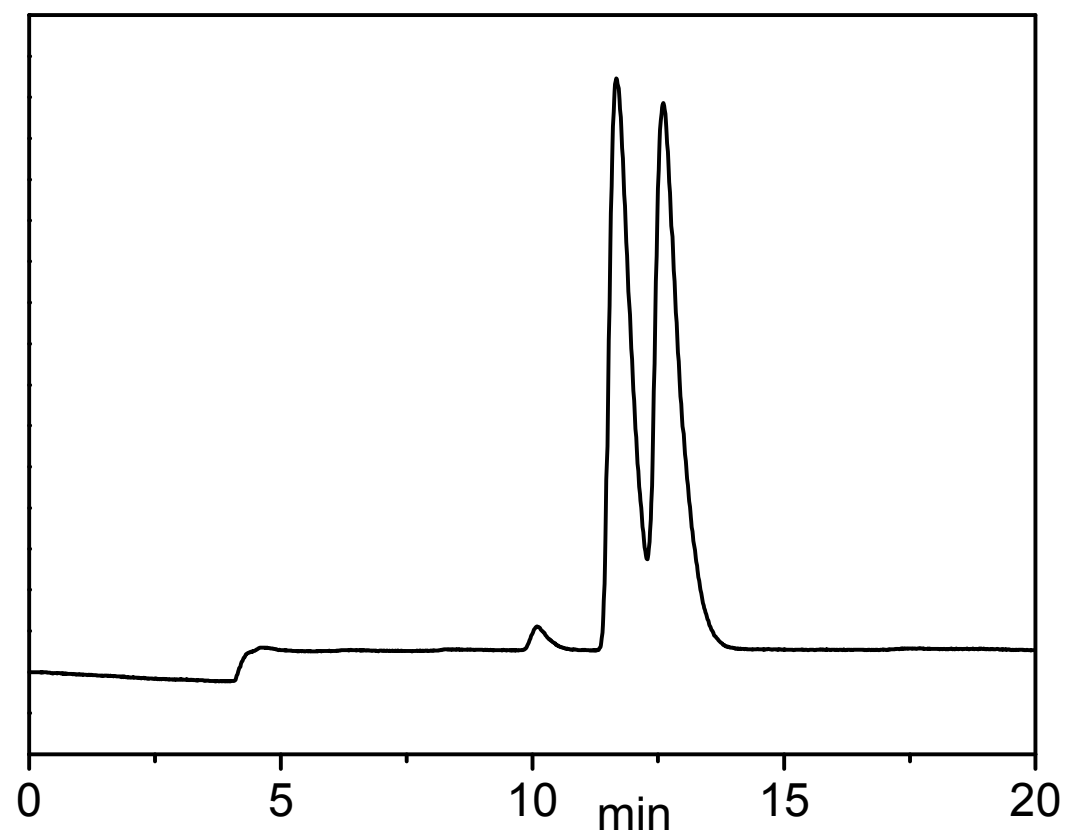

Enantiomerically enriched $\mathbf{3 h}$ from $\mathrm{Cu}-\mathrm{L} 7 / \mathrm{st}-\mathrm{DNA}$ catalyzed reaction:

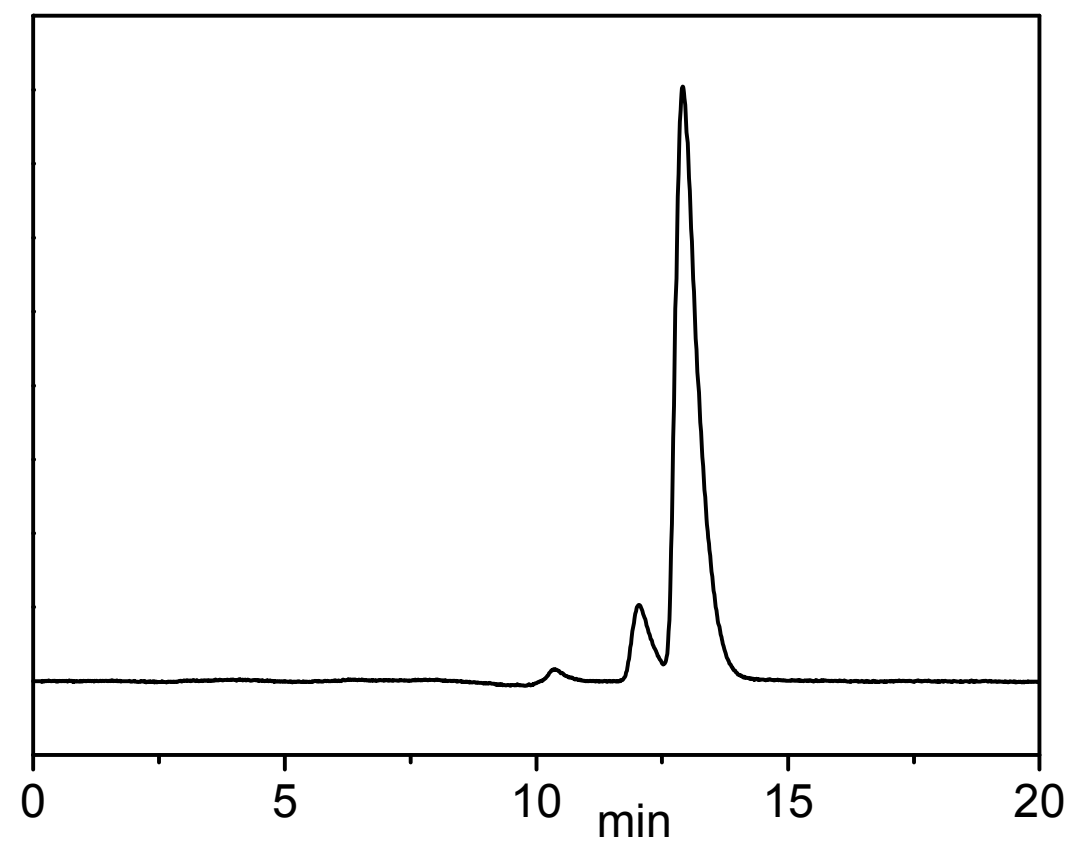




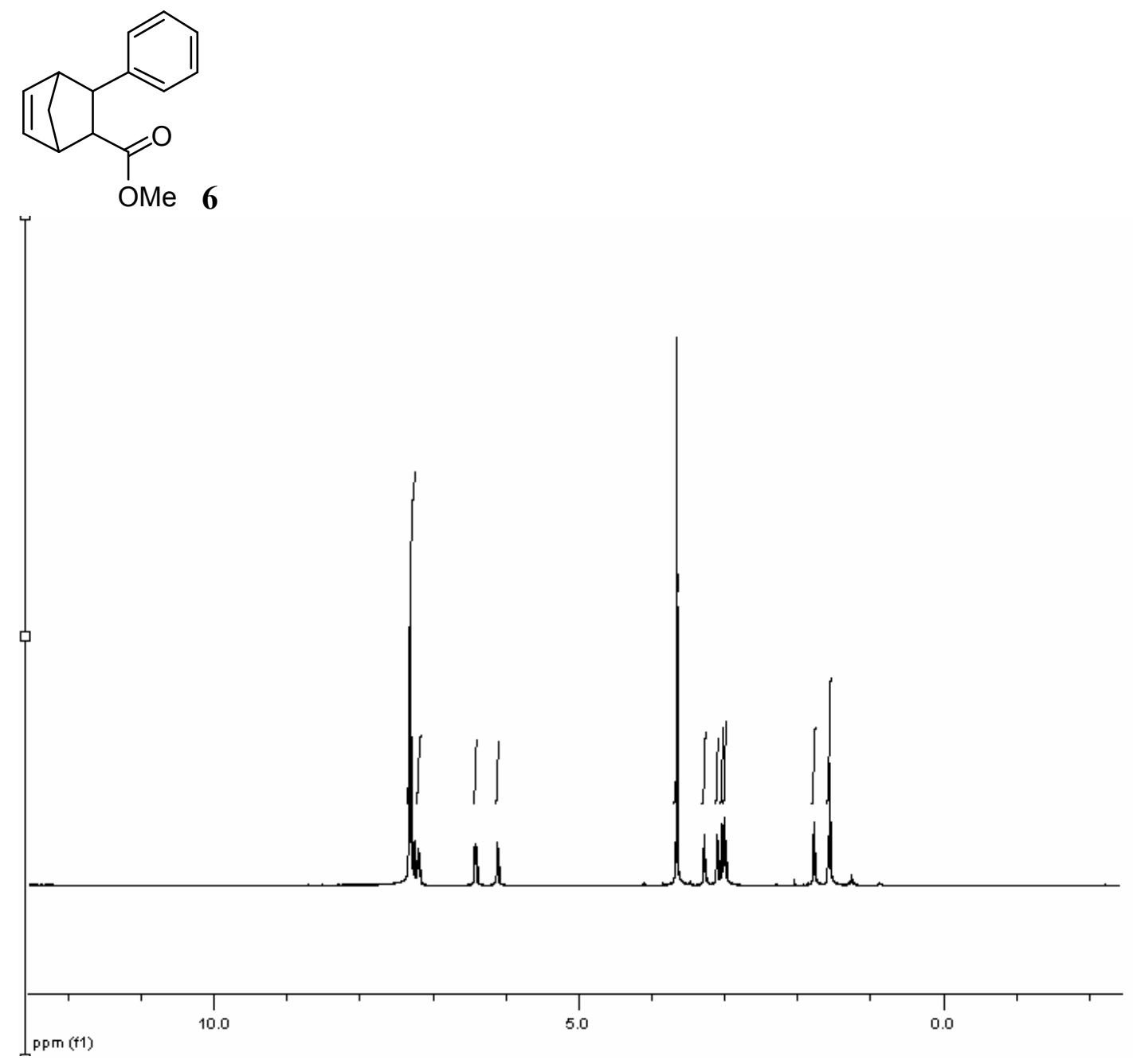

